\title{
The Role of Water Loading and Germanium Content in Germanosilicate Hydrolysis
}

\section{Supporting Information}

Mengting Jin, " Ondřej Vesely, " Christopher James Heard, Martin Kubů, Petr Nachtigall, Jiři Čejka* and Lukáš Grajciar*

Department of Physical and Macromolecular Chemistry, Charles University, Hlavova

8, 12496 Prague 2, Czech Republic.

\#Both authors made equal contributions

*E-mail: lukas.grajciar@natur.cuni.cz, jiri.cejka@natur.cuni.cz

\section{Experimental}

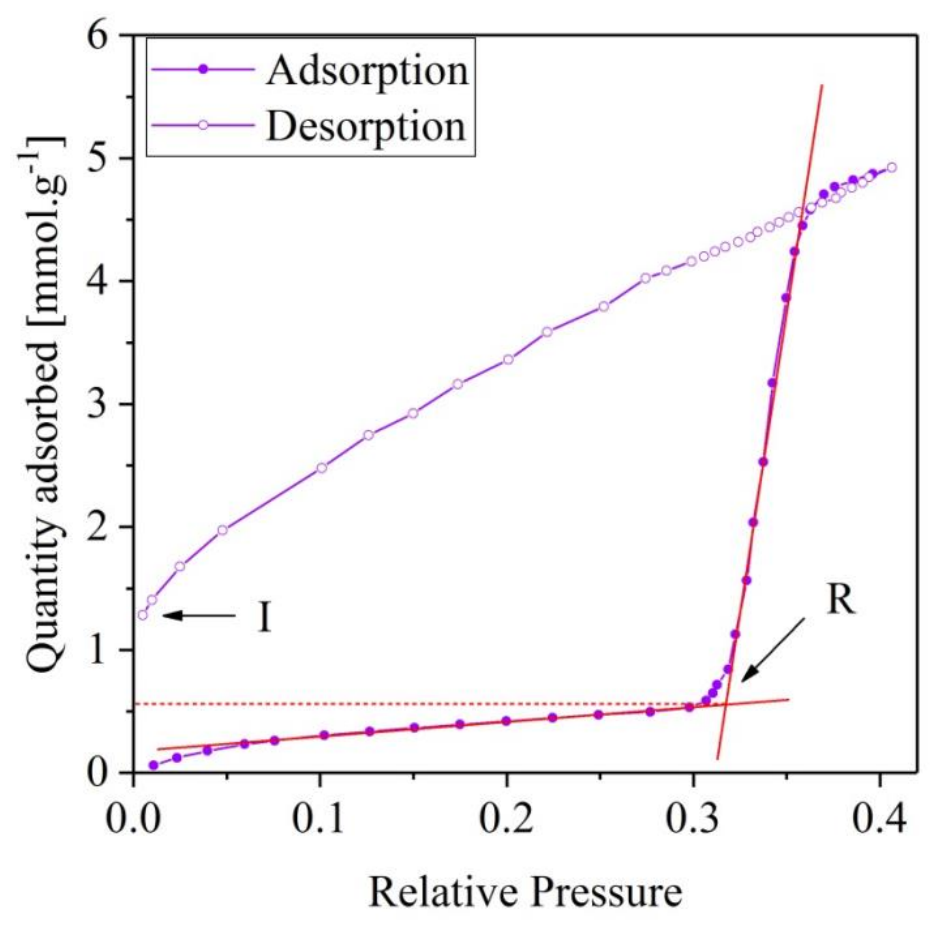

Figure S1: Water vapour adsorption-desorption isotherm of UTL-2.5 illustrating the evaluation of the maximum amount of reversibly adsorbed water $(\mathrm{R})$ and the amount of irreversibly adsorbed water (I). 

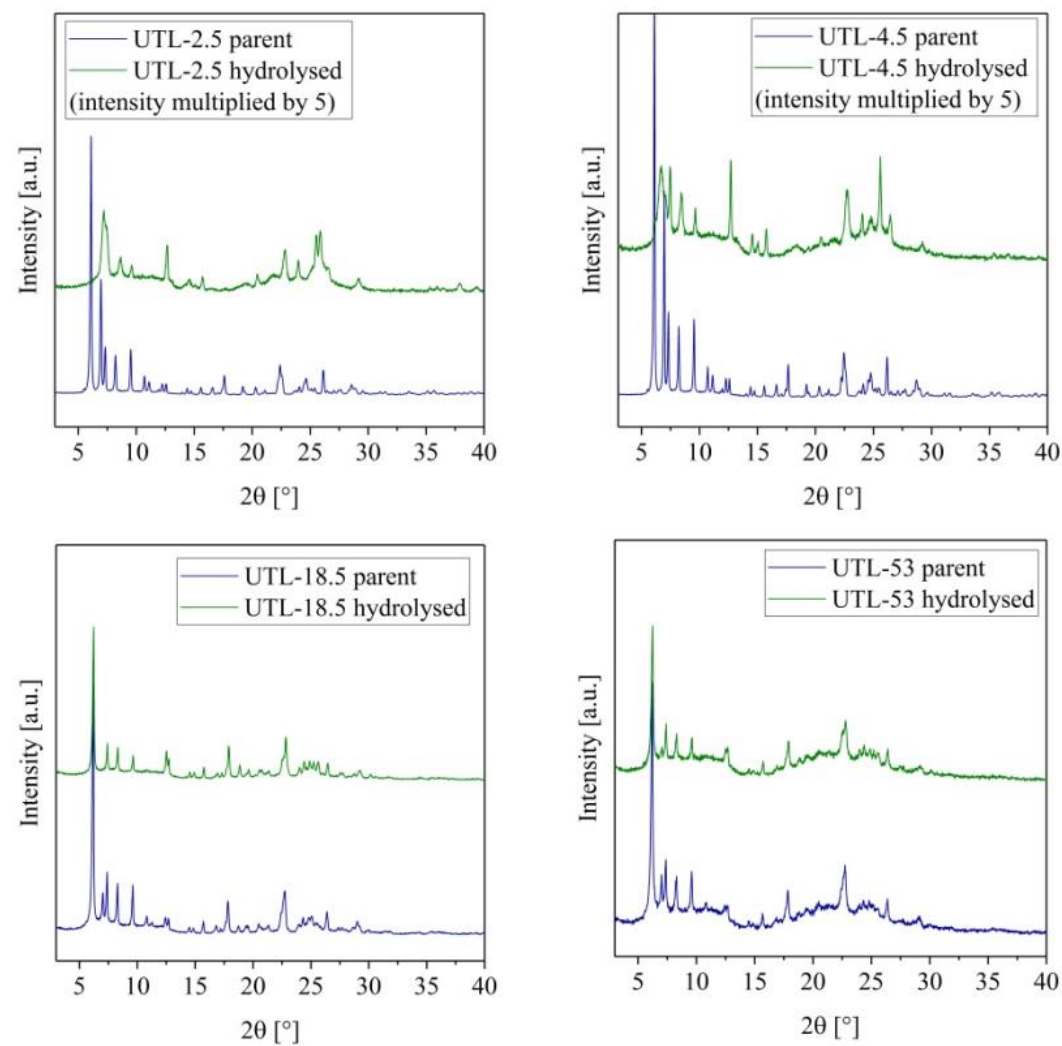

Figure S2: Powder XRD patterns of the four parent UTL samples and samples after 2 cycles of water vapour adsorption.

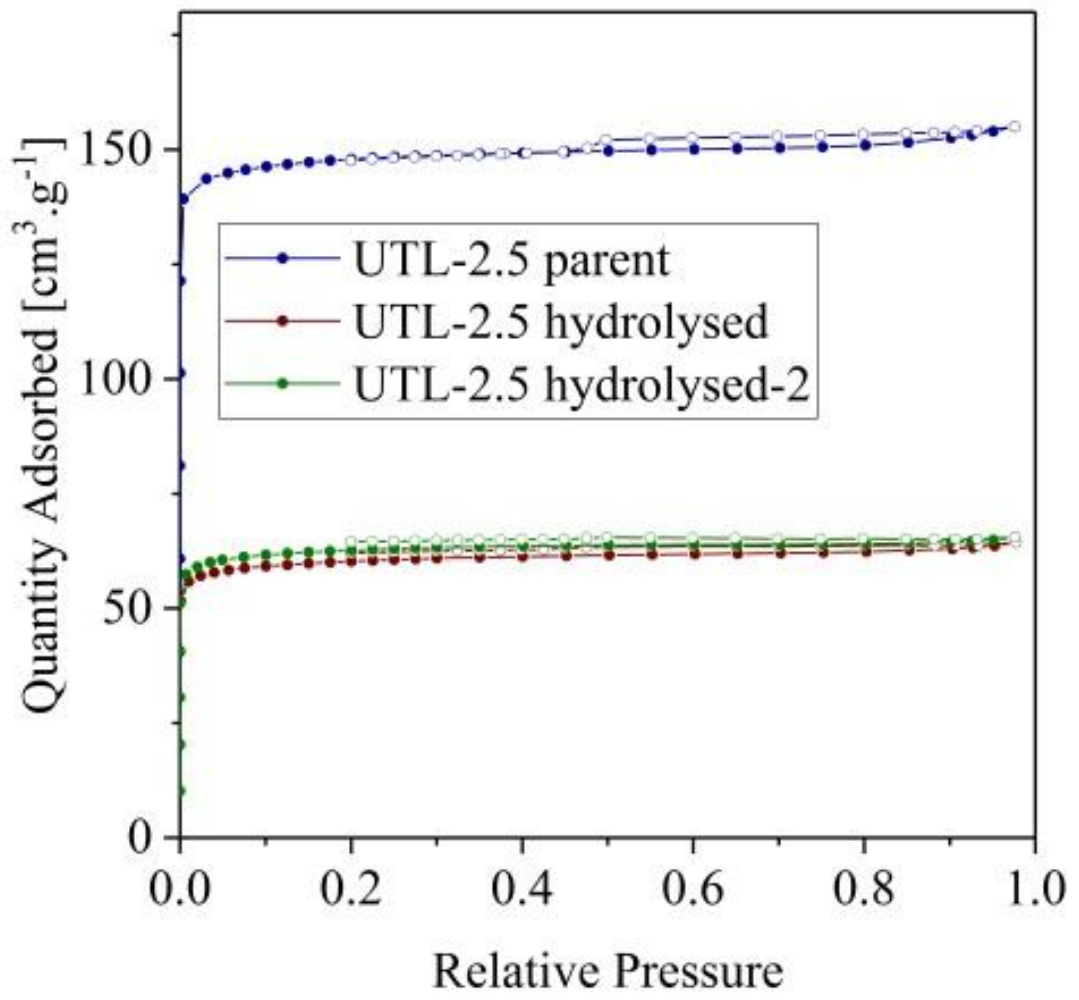



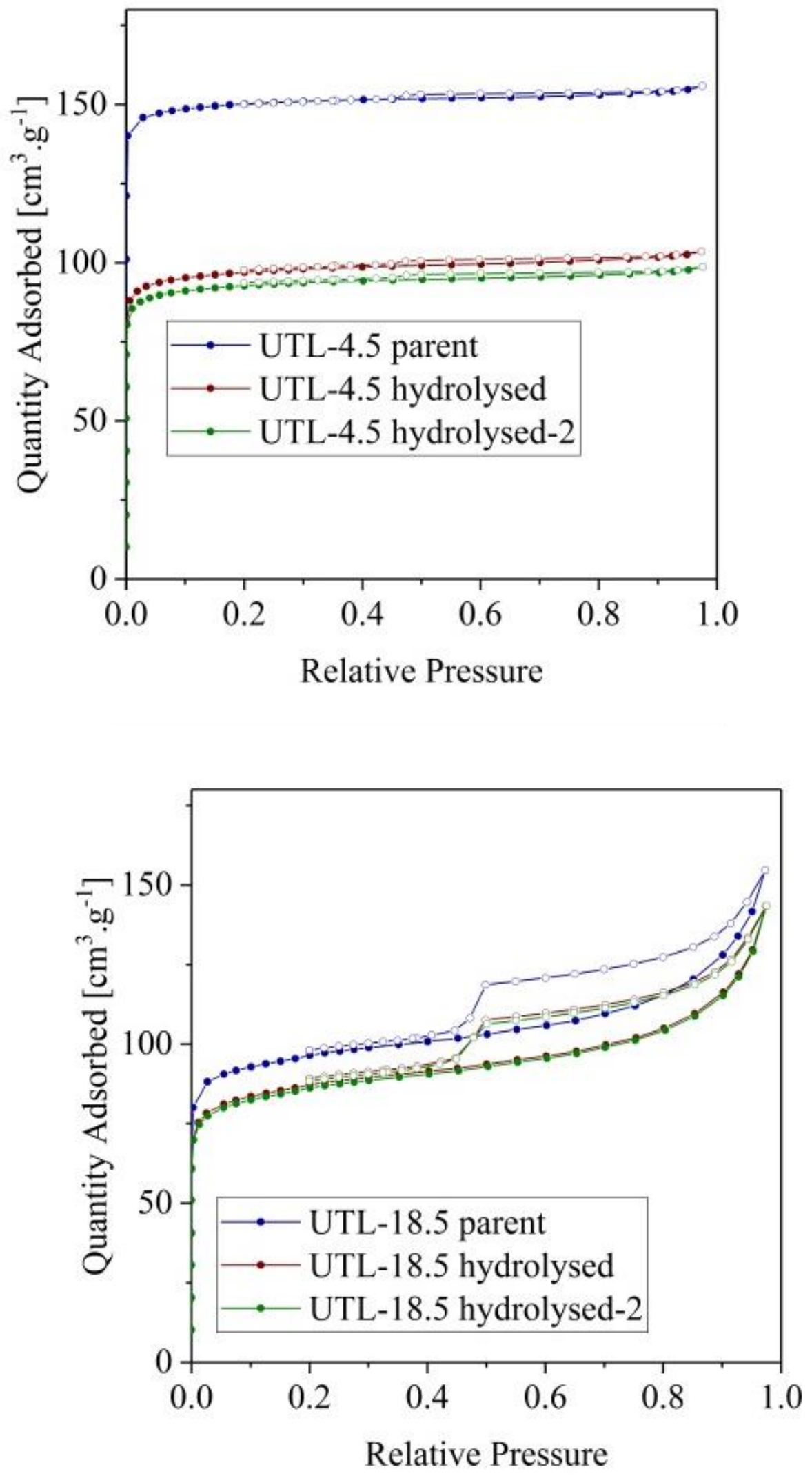


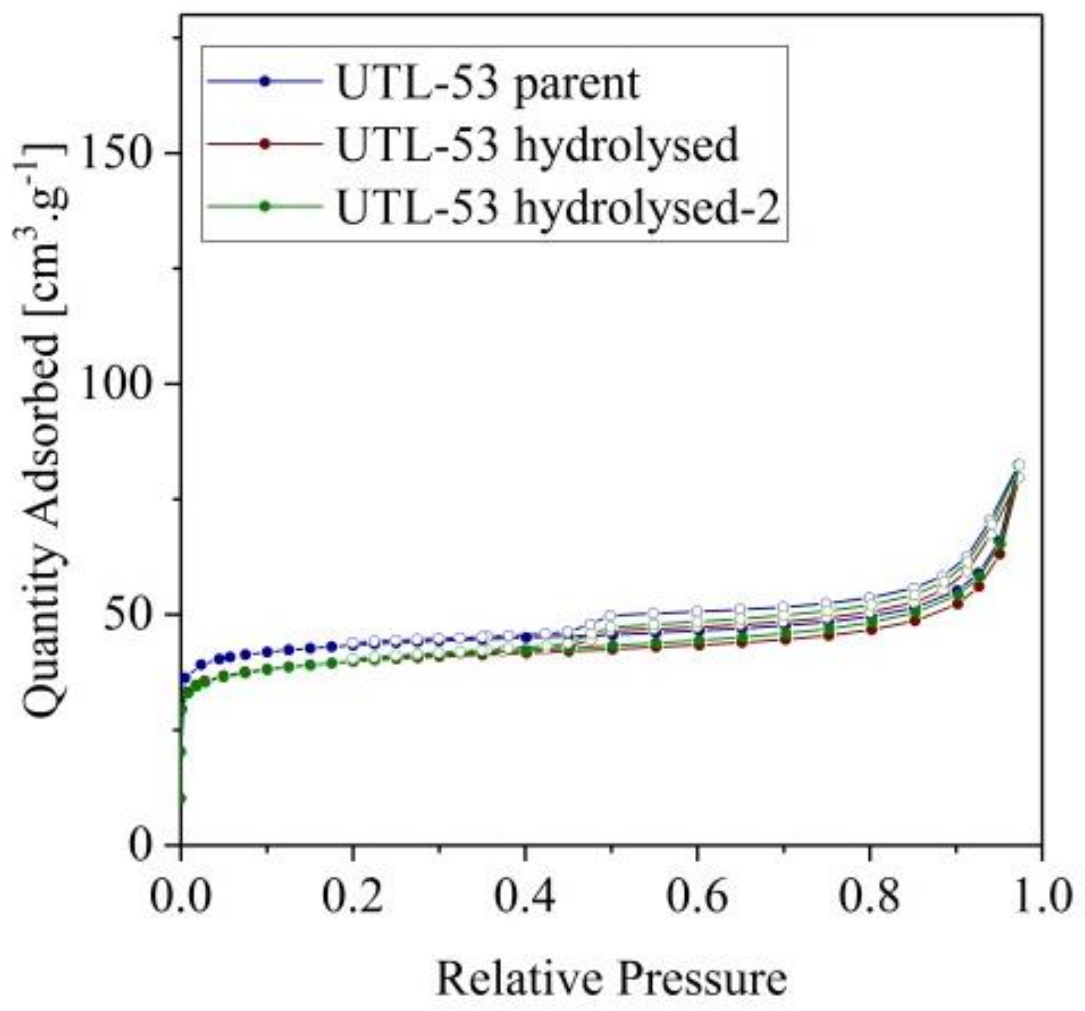

Figure S3: $\mathrm{N}_{2}$ adsorption $(\bullet)$ and desorption ( $(\circ)$ isotherms of the four parent UTL samples and samples after the first and second cycle of water vapour adsorption

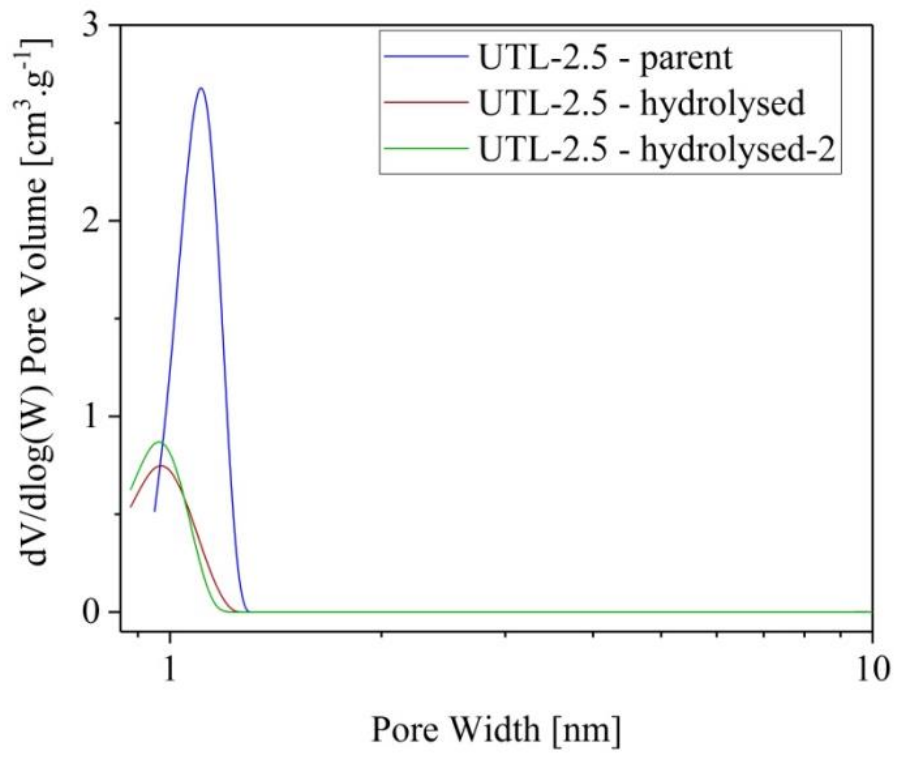

Figure S4: DFTPSD pore size distributions of sample UTL-2.5 before and after 1st and 2nd water vapour adsorption cycles. 
Table S1: Number of water molecules per unit cell at different steps of the adsorptiondesorption experiment

\begin{tabular}{lllll}
\hline Sample & Si/Ge & $\begin{array}{l}\text { Reversible } \\
\text { NH2O/cell }\end{array}$ & $\mathbf{A}_{\max } \mathbf{N}_{\text {H2O/cell }}$ & $\begin{array}{l}\text { Ireversible } \\
\text { NH2O/cell }\end{array}$ \\
\hline UTL-2.5 & 2.50 & 1.64 & 33.38 & 11.78 \\
UTL-4.5 & 4.52 & 2.25 & 28.02 & 10.09 \\
UTL-18.5 & 18.48 & 4.44 & 15.23 & 4.96 \\
UTL-53 & 53.15 & 4.37 & 6.47 & 1.92 \\
\hline
\end{tabular}

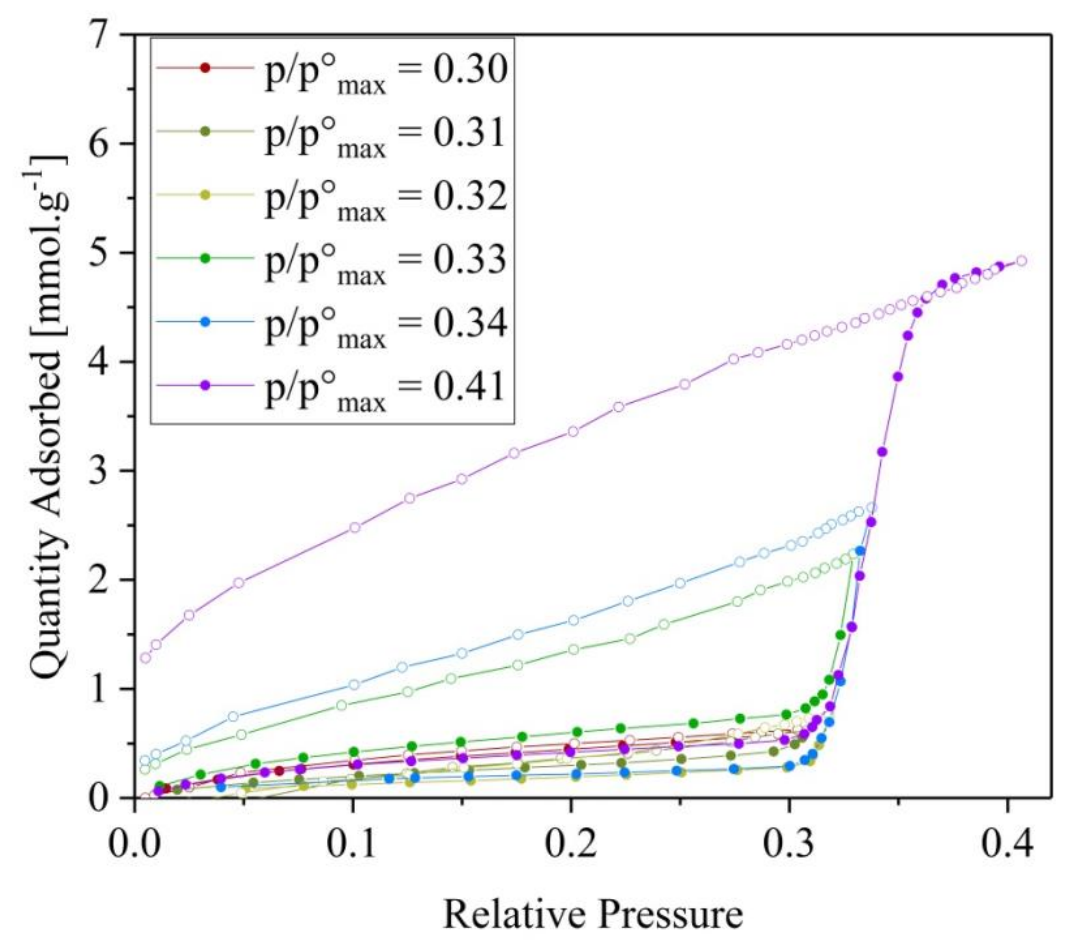

Figure S5: Water-vapour adsorption (•) and desorption (०) isotherms of UTL-2.5 at $20^{\circ} \mathrm{C}$ with maximum $\mathrm{p} / \mathrm{p}_{0}=0.30,0.31,0.32,0.33,0.34$ and 0.41 .

\subsection{Discussion}

The experimental results raised several valid questions which need to be addressed and clarified. However, since they are not related to the aim of the article, we address them separately.

1) What is the elemental composition of the UTL samples after water vapour adsorptiondesorption cycle.

Elemental composition of the bulk material is unaffected by the adsorption because the measurement is performed in closed system. The germanium is removed from framework positions by the hydrolysis and since the newly formed germanium oxide/hydroxide species are 
not volatile, they then remain within the pores as an extra-framework species. In summary, the germanium transitions from framework to extra-framework species but remain within the bulk sample.

2) The adsorption branch of the water-vapour adsorption-desorption isotherm of UTL-2.5 is above the desorption branch at $\mathrm{p} / \mathrm{p} 0=0.3-0.4$. Why?

The irreversible water adsorption in between the $\mathrm{p} / \mathrm{p} 0=0.3-0.4$ causes profound structural changes during the adsorption process. The material undergoes a transformation and its properties change. Therefore, the water desorbs from a material with different structure than it adsorbed onto.

3) What is the difference between the water vapour adsorption experiment compared to the conventional water treatment in ADOR transformation?

The difference between the convential ADOR protocol and conditions of the water vapour adsorption is the water loading. In conventional ADOR the water is used in an excess and works also as an intercalant that separates the layers of the hydrolysed material apart from each other. Here, the low amount of water does not enable for such separation, thus, leading to instant recondensation of the layers, leading to a highly disordered material.

\section{Computational}

\subsection{High water loading model preparation}

In the high water loading regime the solvent water was included into the pore structure, with a density of $\sim 1 \mathrm{~g} / \mathrm{cm}^{3}$, which corresponds to 18 molecules per UTL unit cell. The UTL accessible volume fraction of $21.88 \%$ was taken from the IZA database ${ }^{[1]}$. Molecules were initially placed in the zeolite pore structure by overlapping the unit cell with a cubic water box containing a random packing of $\mathrm{spc}$ water molecules. This was done using the gromacs solvate module ${ }^{[2]}$, with a vdW radius scaling factor adjusted to match the number of molecules required to satisfy the required density of $\sim 1 \mathrm{~g} / \mathrm{cm}^{3}$.

\subsection{Details of free energy calculations.}

The one-dimensional collective variables (CV) were used within slow growth (SG) and thermodynamic integration (TI) simulations to describe the reaction path between reactants and products. The $\mathrm{CV}$ were formed by a combination of bond distances describing formation and breaking of the chemical bonds. In particular, for the axial mechanism of $\mathrm{Ge}-\mathrm{O}_{\mathrm{f}}$ cleavage, the $\mathrm{CV}$ is the norm of the vector consisting of the $\mathrm{Ge}-\mathrm{O}_{\mathrm{w}}$ distance, the $\mathrm{H}_{\mathrm{w}}-\mathrm{O}_{\mathrm{f}}$ distance, and the hydrogen bonds between the solvent waters in the chain. For the S2R mechanism, the CV is the vector consisting of the distance between the neighbouring $\mathrm{Ge}$ atoms and the oxygen atom in the selected water molecule $\left(\mathrm{Ge} 1-\mathrm{O}_{\mathrm{w}}\right.$ and $\left.\mathrm{Ge} 2-\mathrm{O}_{\mathrm{w}}\right)$, and the hydrogen bond between $\mathrm{H}_{\mathrm{w}}$ in the selected water molecule and a neighbouring water molecule. These CVs are depicted in Figure S6. The calculation of free energy barriers and pathways was performed as follows: The SG simulations were used to investigate the irreversible work along the reaction profile defined by the $\mathrm{CV}$, the chosen CV distance was varied linearly along the reaction path by -0.0002 for each step. The TI simulations were employed to generate Helmholtz free energy gradients at a set of between 15 and 35 configurations, which were selected along the SG trajectory fixing the value of the $\mathrm{CV}$ at each point. At each fixed value of the $\mathrm{CV}$, the average value of free energy gradients were obtained from a trajectory $7.5 \mathrm{ps}$ long (with a timestep of $0.75 \mathrm{fs}$ ). The final free energy profile was then generated through integration of the free energy gradient along the 
reaction path from reactant to product. This integration provides the final estimate of the minimum free energy path and thereby the estimate of the Helmholtz free energy barrier and the reaction Helmoholtz free energy is obtained.

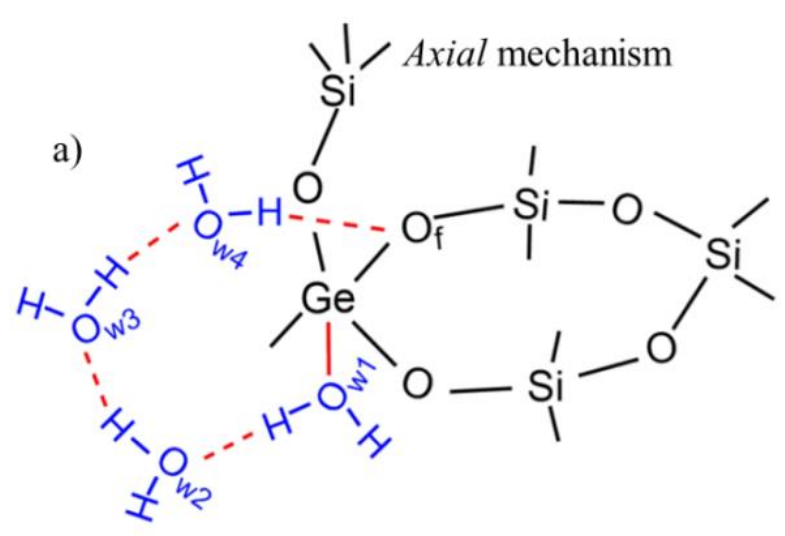

$$
\mathrm{CV}=\sqrt{\sum\left(\gamma_{G e-O_{W_{1}}}\right)^{2}+\left(\gamma_{H_{1}-O_{W_{2}}}\right)^{2}+\left(\gamma_{H_{2}-O_{W_{3}}}\right)^{2}+\left(\gamma_{H_{W_{3}}-O_{W_{4}}}\right)^{2}+\left(\gamma_{H_{4}-O_{f}}\right)^{2}}
$$

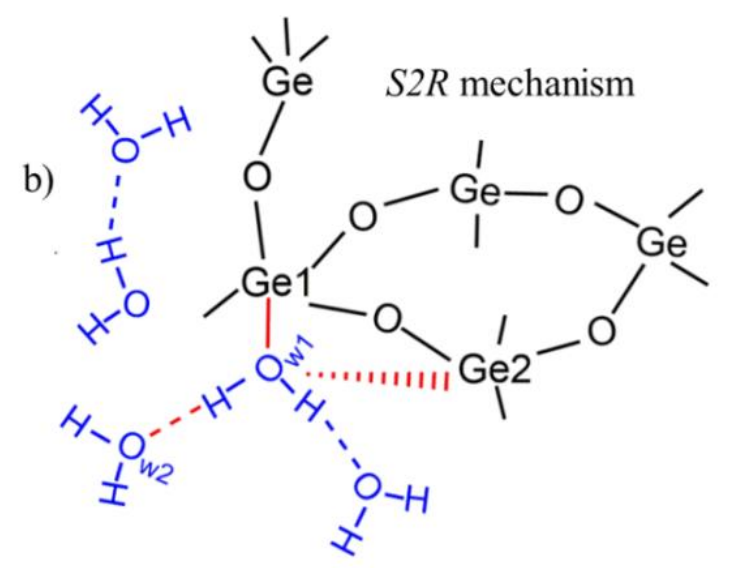

$\mathrm{CV}=\sqrt{\sum\left(\gamma_{G e 1-O_{W 1}}\right)^{2}+\left(\gamma_{G e 2-O_{W 1}}\right)^{2}+\left(\gamma_{H_{11}-o_{W 2}}\right)^{2}}$

Figure S6: The schematic depiction of the collective variables (CV) chosen for the Ge-O bond scission steps in UTL. Bonds involved in the CV are shown in red colour. a) represents the axial mechanism. b) represents the $S 2 R$ mechanism.

\subsection{Physisorption}

Table S2: Summary of adsorption energies $\left[\mathrm{kJ} \cdot \mathrm{mol}^{-1}\right]$ of a single $\mathrm{H}_{2} \mathrm{O}$ molecule over different $\mathrm{T}$ sites in UTL models in the purely siliceous UTL model or with the silicon in the $\mathrm{T}$ site substituted by germanum (1Ge-UTL models), using static DFT calculations. Descriptions of the O-down (see, e.g., Figure S7b) and H-down (see, e.g., Figure S7a) adsorption complexes are provided in the main text.

\begin{tabular}{cccccc}
\hline T sites & \multicolumn{3}{c}{ O-down } & \multicolumn{3}{c}{ H-down } \\
\cline { 2 - 5 } & 1Ge & All Si & $1 \mathrm{Ge}$ & All Si \\
\hline T1 & -25 & -- & -20 & -19 \\
T2 & -30 & -- & -20 & -18 \\
T7 & -24 & -- & -17 & -23 \\
T8 & -22 & -- & -28 & -34 \\
T4 & -38 & -- & -29 & -31 \\
T12 & -- & -- & -22 & -28 \\
\hline
\end{tabular}




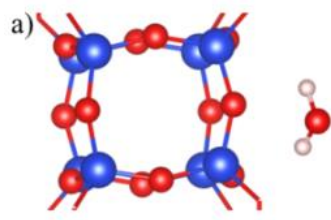

$-19 \mathrm{~kJ} / \mathrm{mol}$

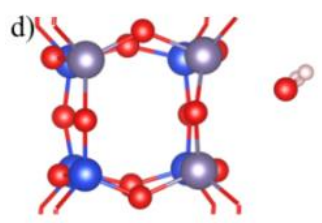

$-32 \mathrm{~kJ} / \mathrm{mol}$

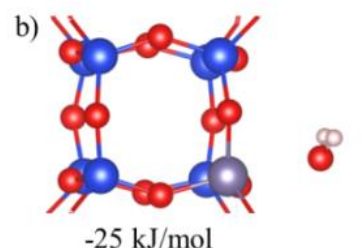

$-25 \mathrm{~kJ} / \mathrm{mol}$

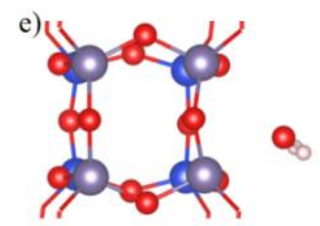

$-36 \mathrm{~kJ} / \mathrm{mol}$

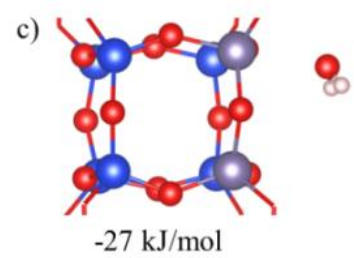

$-27 \mathrm{~kJ} / \mathrm{mol}$

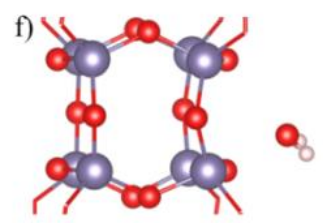

$-34 \mathrm{~kJ} / \mathrm{mol}$

Figure S7: The structures of single water adsorption complexes in a) pure silicon UTL and in UTL models with different amounts of silicon atoms exchanged for germanium, b) 1Ge-UTL, c) 2Ge-UTL, d) 3Ge-UTL, e) 4Ge-UTL, f) 8Ge-UTL. The corresponding adsorption energy is displayed below the structure.

Germanium water affinity from finite temperature AIMD simulations. Water affinity (in the zero water coverage limit) towards germanium Lewis sites appears to diminish with increasing temperature. We carried out short (approx. 20 ps) equilibrium AIMD simulations of water adsorbed in multiple UTL models with increasing germanium content in D4R units $(0$, 1, 2, 3, 4 and 8 germanium atoms in D4R unit - see Figure S7). All AIMD runs were done at $370 \mathrm{~K}$. Visual inspection of the trajectories (see Figure S8 containing trajectory lines) clearly indicate that water preferentially occupies adsorption 'pockets' above the (purely siliceous) 5and 8-rings at the bottom of $12 \mathrm{R}$ and $14 \mathrm{R}$ channels of UTL in-between the two D4R units. Evaluation of mean internal energy $U$ for these adsorption 'pockets' indicate that 'pockets' in $12 \mathrm{R}$ are by approx. $10 \mathrm{~kJ}^{\mathrm{mol}}{ }^{-1}$ more stable than those in 14R (see running averages of internal energy in Fig. S9). The germanium adsorption sites observed in static calculations (see above) are visited during the AIMD simulations, but only very briefly. This is confirmed by partial radial distribution functions of $\mathrm{O}_{\mathrm{w}}-\mathrm{Ge}, \mathrm{O}_{\mathrm{w}}-\mathrm{Si}, \mathrm{H}_{\mathrm{w}}-\mathrm{Ge}$ and $\mathrm{H}_{\mathrm{w}}-\mathrm{Si}$ (see Figure $\mathrm{S} 10$ ) which show only a minor contribution from close $\mathrm{O}_{\mathrm{w}}$-Ge contacts (below $3 \AA$ ). Hence, inclusion of temperature (entropic) effects at $370 \mathrm{~K}$ makes germanium Lewis sites in UTL dynamically unstable, at least in the zero water coverage limit.
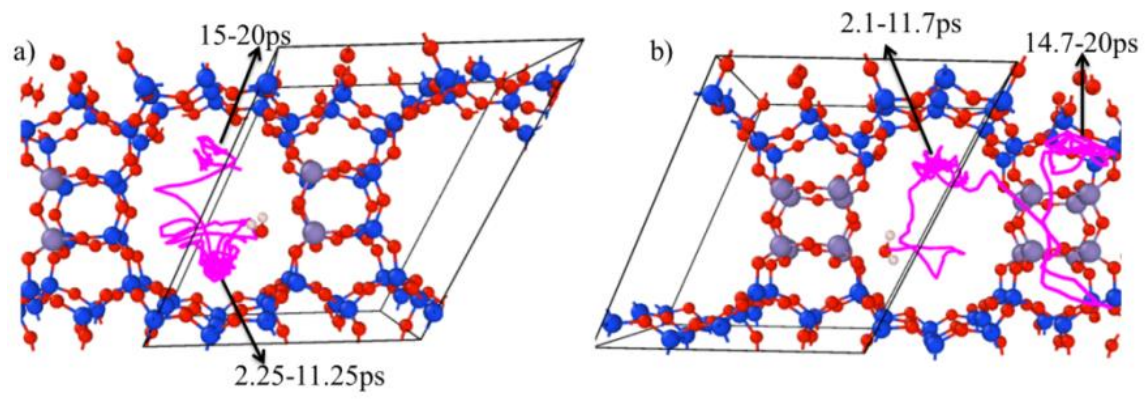

Figure S8: The trajectory lines (pink lines) for one water molecule adsorbed in a) 2Ge-UTL model and b) 8Ge-UTL model during AIMD simulation. For water in 2Ge-UTL, the water stay in the $12 \mathrm{R}$ ring channel throughout the $20 \mathrm{ps}$ AIMD, the water preferentially occupies 
adsorption 'pockets' above 5- and 8-rings at the bottom/top of the $12 \mathrm{R}$ from $2.25 \mathrm{ps}$ to $11.25 \mathrm{ps}$ and from $15 \mathrm{ps}$ to $20 \mathrm{ps}$, respectively. For water in 8Ge-UTL, the water stays in the $12 \mathrm{R}$ channel at first and water 'pockets' above 5- and 8-rings at the bottom/top of the $12 \mathrm{R}$ from $2.1 \mathrm{ps}$ to $11.7 \mathrm{ps}$, then the water moves into $14 \mathrm{R}$ and water 'pockets' above 5- and 8-rings at the bottom/top of the $14 \mathrm{R}$ from $14.7 \mathrm{ps}$ to $20 \mathrm{ps}$. This dynamics is reflected in the averages of internal energy $U$ as shown in Figure S9.
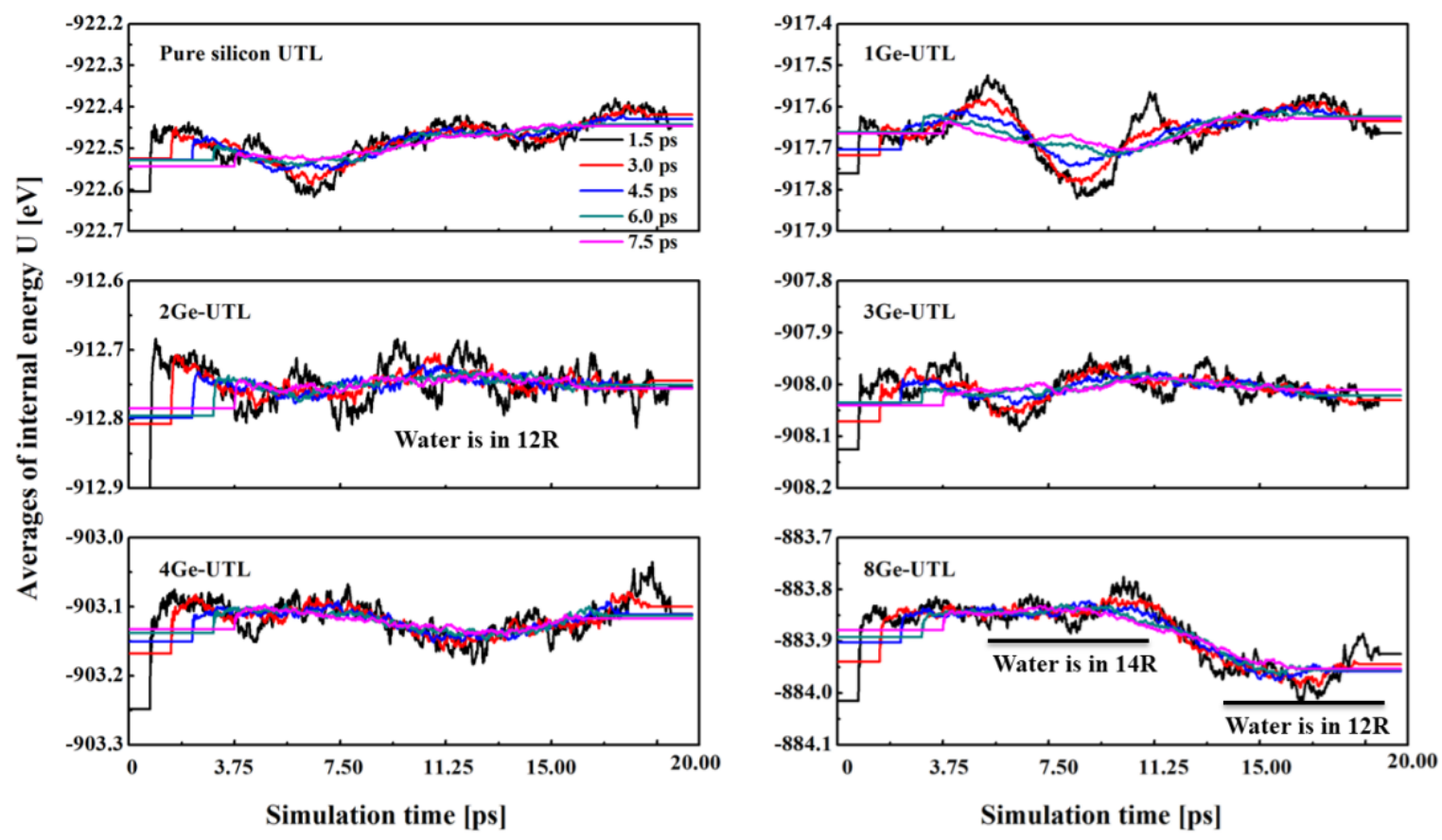

Figure S9: The running averages of the internal energy $U$ from equilibrium AIMD simulations of one water adsorbed in nGe-UTL models ( $n=0,1,2,3,4$ and 8) with increasing germanium content in D4R units. The running averages are calculated over a varying length of averaging time, from $1.5 \mathrm{ps}$ to $7.5 \mathrm{ps}$. The running average value at the particular time frame corresponds to average over an averaging window centered at a particular time frame (e.g., the value for a $1.5 \mathrm{ps}$ averaging window (black line) that is shown at $3.75 \mathrm{ps}$ corresponds to the average from 3 ps to $4.5 \mathrm{ps}$ ). Values for the initial parts of the simulations (horizontal lines) that are shorter than half of the averaging window length are not evaluated, rather the first valid value of running average is taken instead (e.g. for a $1.5 \mathrm{ps}$ averaging window, the running average values for the first $1.5 \mathrm{ps}$ are constant and equal to the value at $1.5 \mathrm{ps}$ ) - a similar approximation applies to final parts of the simulations. 
a)
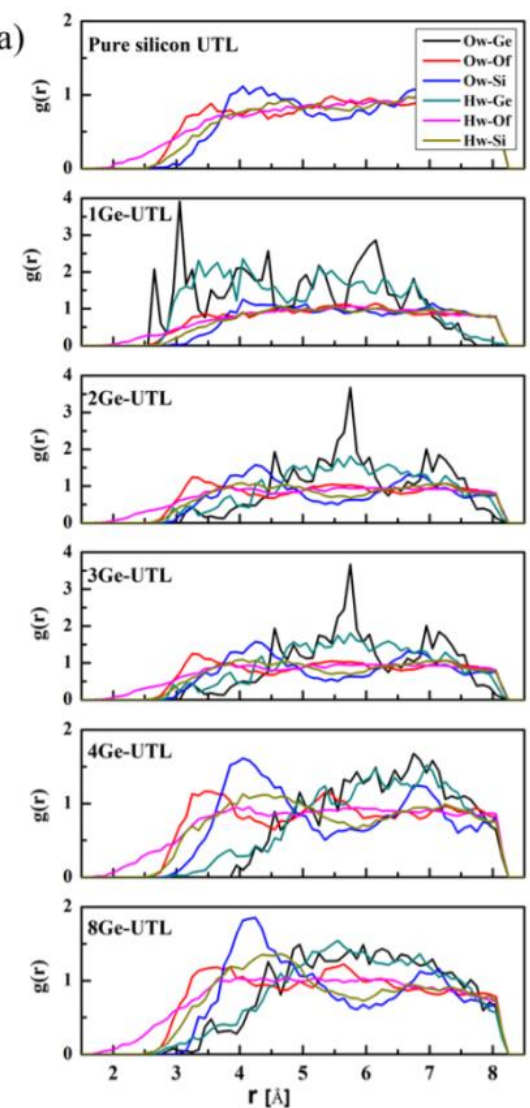

b)
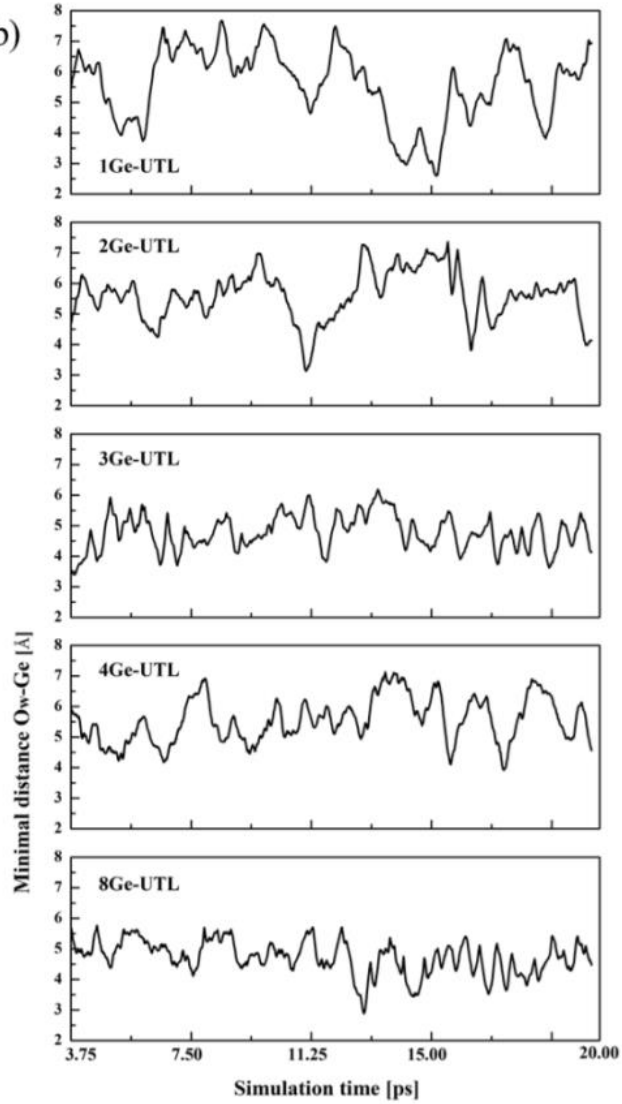

Figure S10: a) The partial radial distribution function between selected "atoms in water" and "atoms in the zeolite framework" considering multiple nGe-UTL models ( $\mathrm{n}=0,1,2,3,4$ and 8): $\mathrm{O}$ atom from water and all $\mathrm{Ge}$ atoms $\left(\mathrm{O}_{\mathrm{w}}-\mathrm{Ge}\right.$ - black line); $\mathrm{O}$ atom from water and all $\mathrm{O}$ atoms from framework $\left(\mathrm{O}_{\mathrm{w}}-\mathrm{O}_{\mathrm{f}}-\right.$ red line $)$; $\mathrm{O}$ atom from water and all $\mathrm{Si}$ atoms $\left(\mathrm{O}_{\mathrm{w}}-\mathrm{Si}\right.$ - blue line); $\mathrm{H}$ atom from water and all $\mathrm{Ge}$ atoms $\left(\mathrm{H}_{\mathrm{w}}-\mathrm{Ge}\right.$ - green line); $\mathrm{H}$ atom from water and all $\mathrm{O}$ atoms from framework $\left(\mathrm{H}_{\mathrm{w}}-\mathrm{O}_{\mathrm{f}}\right.$ - pink line); and $\mathrm{H}$ atom from water and all $\mathrm{Si}$ atoms $\left(\mathrm{H}_{\mathrm{w}}-\mathrm{Si}\right.$ yellow line). b) The minimal distance between an $\mathrm{O}$ atom from a water molecule and all $\mathrm{Ge}$ atoms during AIMD simulation for different nGe-UTL models ( $\mathrm{n}=1,2,3,4$ and 8).

Effect of germanium content on water adsorption complex structure. The cooperative effect of adjacent germanium adsorption sites on water affinity in zero coverage limit appears to be minor but clearly distinguishable. Starting from 3Ge-UTL model with three germaniums clustered in S4R, water is able to interact with both germaniums forming a D4R edge inducing formation of two penta-coordinated germanium centers by occupying one of the vertices of the trigonal bipyramid (see Figure S11b). Admittedly, the perturbation of the initial tetrahedral arrangement of $\mathrm{Ge}$ centers towards trigonal bipyramid is rather mild (the two $\mathrm{O}_{\mathrm{w}}-\mathrm{Ge}$ close contacts are approx. 2.471-2.986 and 3.094-3.782 $\AA$, respectively) but the tendency of water to insert in-between two Ge atoms is quite clear. The fact that we do not observe similar behavior for the 2Ge-UTL model seems to be related to increased flexibility of the D4R unit at higher Ge content. In particular, we relate it to sharper Ge-O-Ge angles (in range of $125-135^{\circ}$ ) in comparison to Ge-O-Si angles $\left(135-150^{\circ}\right)$ in $\mathrm{D} 4 \mathrm{R}$, which allow for facile formation of (two) adjacent trigonal bipyramids. 

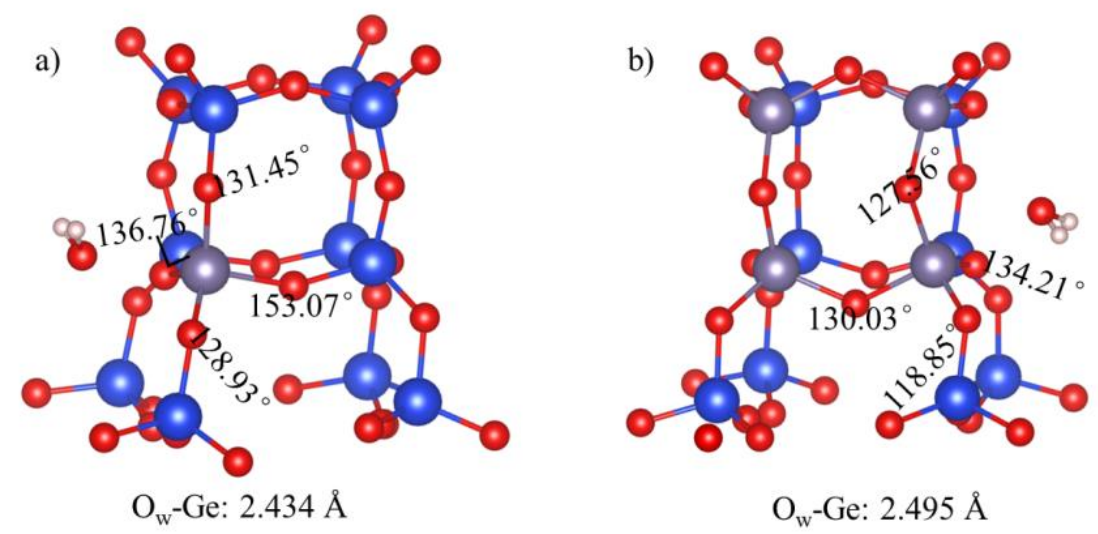

Figure S11: The most stable structure of water O-down adsorption complexes including Ge$\mathrm{O}-\mathrm{Si} / \mathrm{Ge}$ angles, $\mathrm{O}_{\mathrm{w}}$-Ge bond lengths and adsorption energies. a) 1Ge-UTL, and b) 4Ge-UTL models.

\subsection{Chemisorption at low water regime}

Reaction profiles for $Q^{4}->Q^{3}$ step following equatorial(-inversion) mechanism in Ge-poor UTL models. Figure S12 summarizes results for the equatorial $Q^{4}->Q^{3}$ step for all inequivalent oxygens adjacent to three example T sites in D4R unit (T1), adjacent to D4R unit (T7) and the layer (T4). Note that the inversion following the formation of equatorial $\mathrm{Q}^{3}$ products is not feasible for all framework Ge-O bonds, since for some of the symmetrically inequivalent $\mathrm{Ge}$ $\mathrm{O}$ bonds (T1- $\{\mathrm{O} 1, \mathrm{O} 2\}, \mathrm{T} 4-\{\mathrm{O} 15, \mathrm{O} 18, \mathrm{O} 19\}, \mathrm{T} 7-\{\mathrm{O} 1, \mathrm{O} 19\})$, the inversion ends up with the germanol group in large steric repulsion with the framework. This is true in particular for the $\mathrm{T}$ site(s) located in the UTL layer. In case of favorable inversion steps (T1- $\{\mathrm{O} 3, \mathrm{O} 4\}, \mathrm{T} 4-\{\mathrm{O} 20\}$, $\mathrm{T} 7-\{\mathrm{O} 14, \mathrm{O} 21\})$, the inversion is associated with an activation barrier of approx. $35-45 \mathrm{~kJ}^{-\mathrm{mol}^{-}}$ ${ }^{1}$, making the overall effective barrier for breaking the first $\mathrm{Ge}-\mathrm{O}$ bond in UTL as high as 100$120 \mathrm{~kJ} . \mathrm{mol}^{-1}$. We note that similar considerations are applicable also for the axial mechanism, i.e., that the axial reaction mechanism will not lead to stable products for $\mathrm{O} 1$ and $\mathrm{O} 2$ oxygens. The framework topology is such that axial products would have a germanol group pointing either inside the D4R unit (O1) or in the $t$-non composite building unit $(\mathrm{O} 2)$, respectively ${ }^{[1]}$.

Hypothesis about the instability of the equatorial product. The instability of the equatorial product is probably related to the strain induced by the formation of two silanol/germanol groups nearby that would like to occupy very similar position in space occupying one of the $\mathrm{SiO}_{4} / \mathrm{GeO}_{4}$ tetrahedron vertex, and which does not seem to be compensated for by the hydrogen bonding between the germanol/silanol groups. In $\mathrm{Q}^{2} \mathrm{Si} / \mathrm{Ge}$ (or $\mathrm{Q}^{1}$ and $\mathrm{Q}^{0}$ ) the $\mathrm{SiO}_{4} / \mathrm{GeO}_{4}$ tetrahedron can rotate almost freely (except for probably minor hydrogen bond reformation costs) about the axis defined by two framework oxygens $\mathrm{O}_{\text {fr }}$ atoms on $\mathrm{Q}^{2}$ center still bound to the framework. Hence no, additional inversion barriers need to be overcome (see Figure S13). This is not possible for the $\mathrm{Q}^{3}$ center which does not have this rotation freedom and the hydrogen bond stabilization between silanol/germanols groups is not enough to offset this repulsive strain. The strain is largest in D4R but is relevant also for D4R-adjacent and layer sites (T4, T7) as well as illustrated by low stabilizations of equatorial products in Figure S12. 
a)

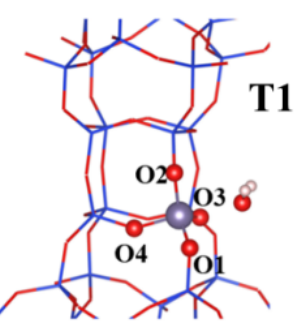

b)

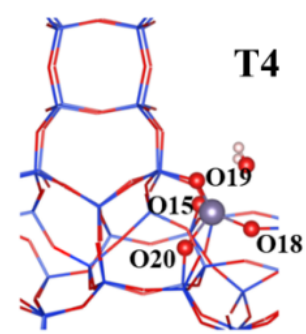

c)

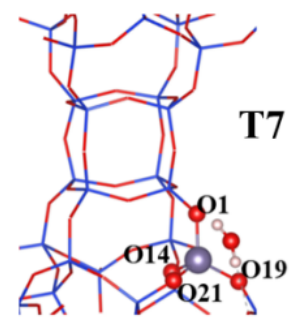

T4
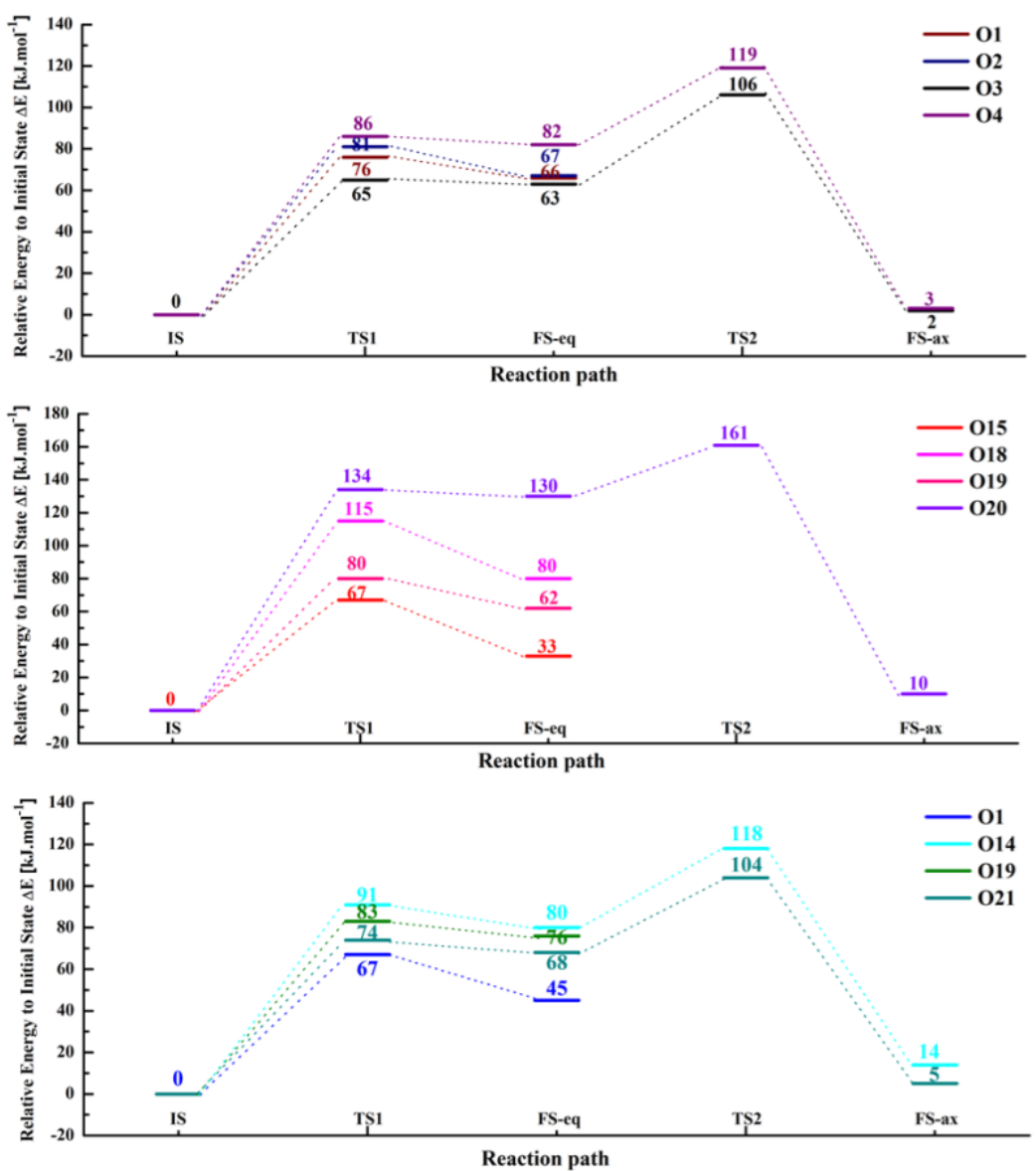

Figure S12: The reaction profiles for equatorial-(inversion) mechanism for the four symmetrically inequivalent Ge-O bonds for 1Ge-UTL model with germanium substituted at: a) T1 site (in the D4R), b) T4 site (in the layer), and c) T7 site (adjacent to the D4R).

Further hydrolytic steps towards full degermanation in Ge-poor UTL models. We also calculated later hydrolysis steps $\left(\mathrm{Q}^{3}->\mathrm{Q}^{2}, \mathrm{Q}^{2}->\mathrm{Q}^{1}\right.$ and $\mathrm{Q}^{1}->\mathrm{Q}^{0}$ steps $)$ for $\mathrm{T} 1$ site in a Ge-poor environment according to the equatorial mechanism, by adding one water to the system in each step, leading to complete hydrolysis of a $\mathrm{Ge}$ atom from the framework (see Figure S13). The reaction energies for later equatorial steps $\left(E_{r}=(-3)-(+24) \mathrm{kJ} \cdot \mathrm{mol}^{-1}\right)$ are much more favorable than for the first $Q^{4}->Q^{3}$ step and thus do not necessitate the inversion step to stabilize the products. The products of later steps $\left(\mathrm{Q}^{2}, \mathrm{Q}^{1}, \mathrm{Q}^{0}\right)$ apparently benefit from the larger flexibility of the partially hydrolyzed Ge center, being able to rotate away from the alignment optimal for the reverse dehydroxylation. The reaction barriers for later steps tend to increase with the degree of hydroxylation from $74 \mathrm{~kJ} \cdot \mathrm{mol}^{-1}$ for $\mathrm{Q}^{3}{ }^{-}>\mathrm{Q}^{2}$ step up to $84-83 \mathrm{~kJ} \cdot \mathrm{mol}^{-1}$ for $\mathrm{Q}^{2}->\mathrm{Q}^{1}$ and $\mathrm{Q}^{1}{ }^{-}>\mathrm{Q}^{0}$ steps, however, they still stay below the effective barrier for the first hydrolytic $Q^{4}->Q^{3}$ step. Hence, the initial $Q^{4}->Q^{3}$ step at low water concentration limit appears to be the rate-limiting step. Thus, it is reasonable to assume that the hydrolysis (with the barrier just above the 100 $\mathrm{kJ} . \mathrm{mol}^{-1}$ ) in low water concentration limit will not proceed at standard conditions ${ }^{[3]}$. 


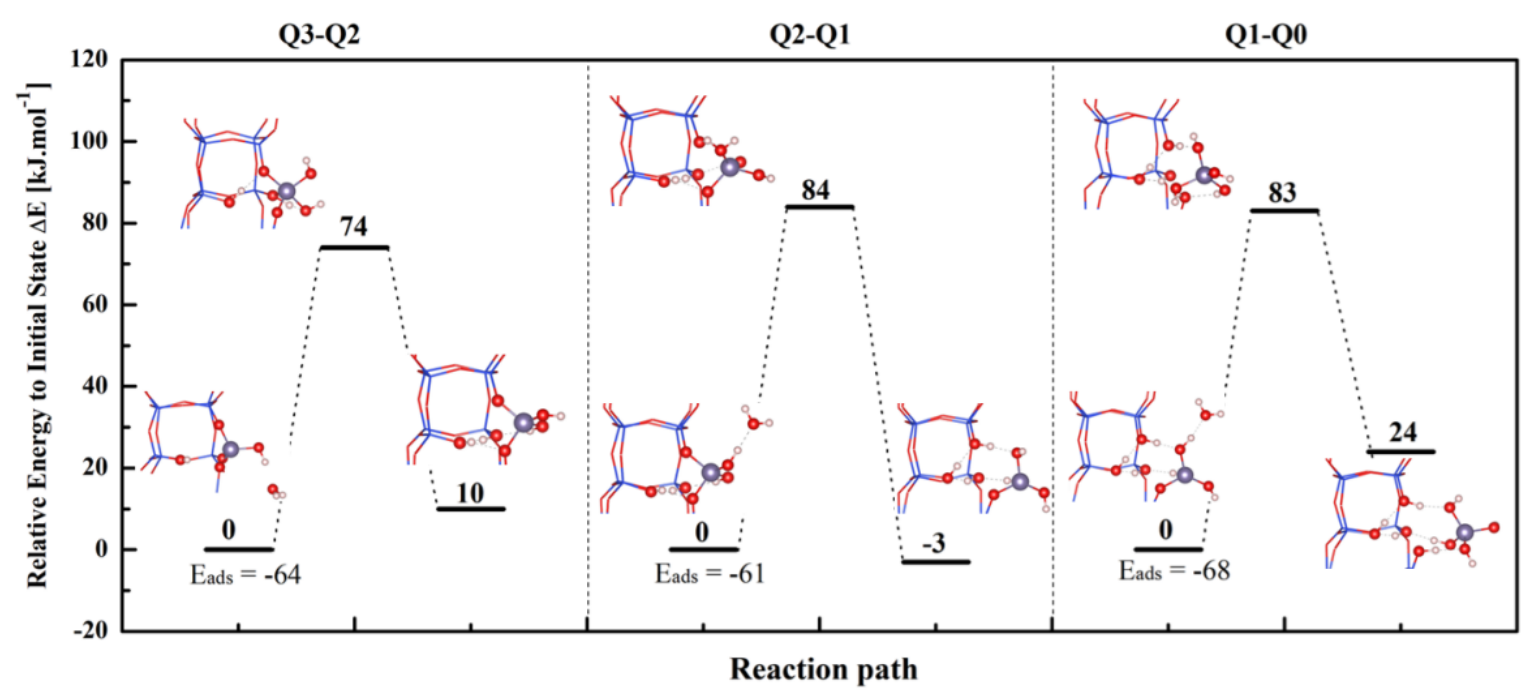

Figure S13: The structures and relative energies of stationary points for further (most favorable) hydrolysis steps all the way from $\mathrm{Q}^{3} \mathrm{Ge} \rightarrow \mathrm{Q}^{0} \mathrm{Ge}$ for $\mathbf{1 G e - U T L}$ model with germanium substitution at the $\mathrm{T} 1$ site. These steps follow the equatorial mechanism. Eads denotes the waterUTL adsorption energies. The energies of each reactant, i.e., of the water- $\mathrm{Q}^{3} \mathrm{Ge} / \mathrm{Q}^{2} \mathrm{Ge} / \mathrm{Q}^{1} \mathrm{Ge}-$ UTL adsorption complexes, is set to zero.

Alternative and further hydrolytic steps for Ge-rich UTL model. Figure S14a shows the results for the rather competitive initial hydrolytic steps in the Ge-rich 8Ge-UTL model, namely equatorial-inversion and geminal steps. Figure S14b then depicts the possible further hydrolytic step originating from the geminal product. This hydrolysis of the Ge-O bond on the Ge center hosting the $\mathrm{Ge}-\left(\mathrm{O}_{\mathrm{fH}} \mathrm{H}_{\mathrm{w}}\right)\left(\mathrm{O}_{\mathrm{w}} \mathrm{H}_{\mathrm{w}}\right)-\mathrm{Ge}$ motif has a similar barrier to the previous hydrolytic step but is now very exothermic $\left(\mathrm{E}_{\mathrm{r}}=-49 \mathrm{~kJ} \cdot \mathrm{mol}^{-1}\right)$, with the product reminiscent of the axial $\mathrm{Q}^{3}$ product in the Ge-poor case. The product keeps the double geminal germanol motif and is apparently stabilized by the internal germanol-germanol hydrogen bond.

a)

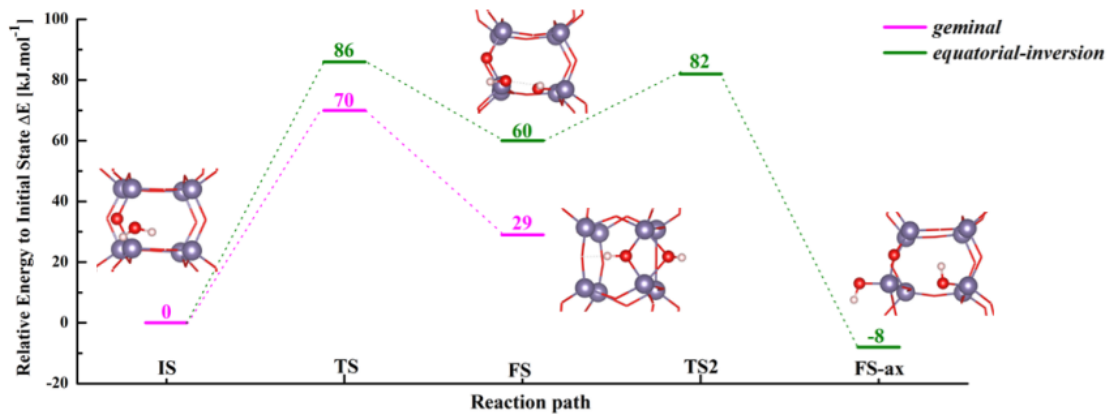

b)

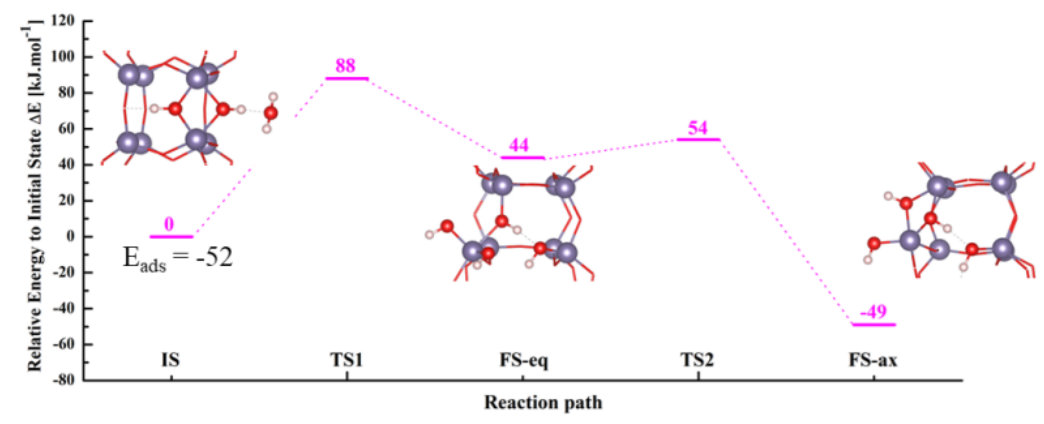


Figure S14: a) The reaction profile with representative structures for initial hydrolytic steps in the Ge-rich 8Ge-UTL model following the equatorial-inversion (green line) and geminal mechanisms (pink line). b) Further hydrolytic step originating from the geminal product and ending up in a $\mathrm{Q}^{3} \mathrm{Ge}$ product. The energies of each reactant, i.e., of the water-UTL adsorption complexes, is set to zero.

Assessment of the framework hydrophilicity after the first hydrolytic step. To quantify the water affinity of defects formed after (partial) hydrolysis we considered models in which a single water molecule adsorbs on the double geminal germanol product of 8Ge-UTL model, and on the axial and equatorial products of the 1Ge-UTL model (see Figs. S13-14). The water molecule forms a hydrogen bond (HB) with the germanol group of the hydrolytic intermediates, with water oxygen $\left(\mathrm{O}_{\mathrm{w}}\right)$ acting as $\mathrm{HB}$ acceptor and the germanol oxygen $\left(\mathrm{O}_{\mathrm{Ge}}\right)$ as $\mathrm{HB}$ donor, i.e., the $\mathrm{Ge}-\mathrm{O}_{\mathrm{Ge}} \mathrm{H} \cdots \mathrm{O}_{\mathrm{w}}-\mathrm{H}_{2}$ motif is formed. An alternative $\mathrm{HB}$ arrangement with $\mathrm{O}_{\mathrm{w}}$ as $\mathrm{HB}$ donor and $\mathrm{O}_{\mathrm{Ge}}$ as $\mathrm{HB}$ acceptor is approx. 16-35 kJ.mol-1 less stable (see Table S4). The

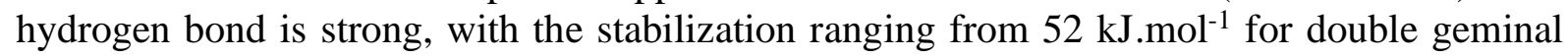
germanol in 8Ge-UTL model up to $68 \mathrm{~kJ}$. $\mathrm{mol}^{-1}$ for the $\mathrm{Q}^{1}$ equatorial product in the 1Ge-UTL case (Figure S13). Such stabilization is already comparable to the stabilization of a water molecule in the liquid water ${ }^{[4-5]}$ (approx. 60-70 $\mathrm{kJ} \mathrm{mol}^{-1}$ at room temperature since water forms approx. $3.5 \mathrm{HBs}$ in the liquid, each approx. $20 \mathrm{~kJ} \cdot \mathrm{mol}^{-1}$ strong) or only somewhat lower than the stabilization of water on the Brönsted acid sites in zeolites ${ }^{[6]}$ (approx. $80 \mathrm{~kJ}^{-\mathrm{mol}^{-1}}$ ). And such water stabilization is approx. $15-30 \mathrm{~kJ}^{-\mathrm{mol}^{-1}}$ larger than for the most stable Ge Lewis acid sites found in the pristine UTL models (see Table S3), increasing the UTL affinity towards water almost two-fold.

Table S3: Structures and adsorption energies of various water adsorption complexes formed from the product of the first hydrolysis step of the $\mathbf{1 G e - U T L}$ model, i.e., on the axial $\mathrm{Q}^{3} \mathrm{Ge}$ product.

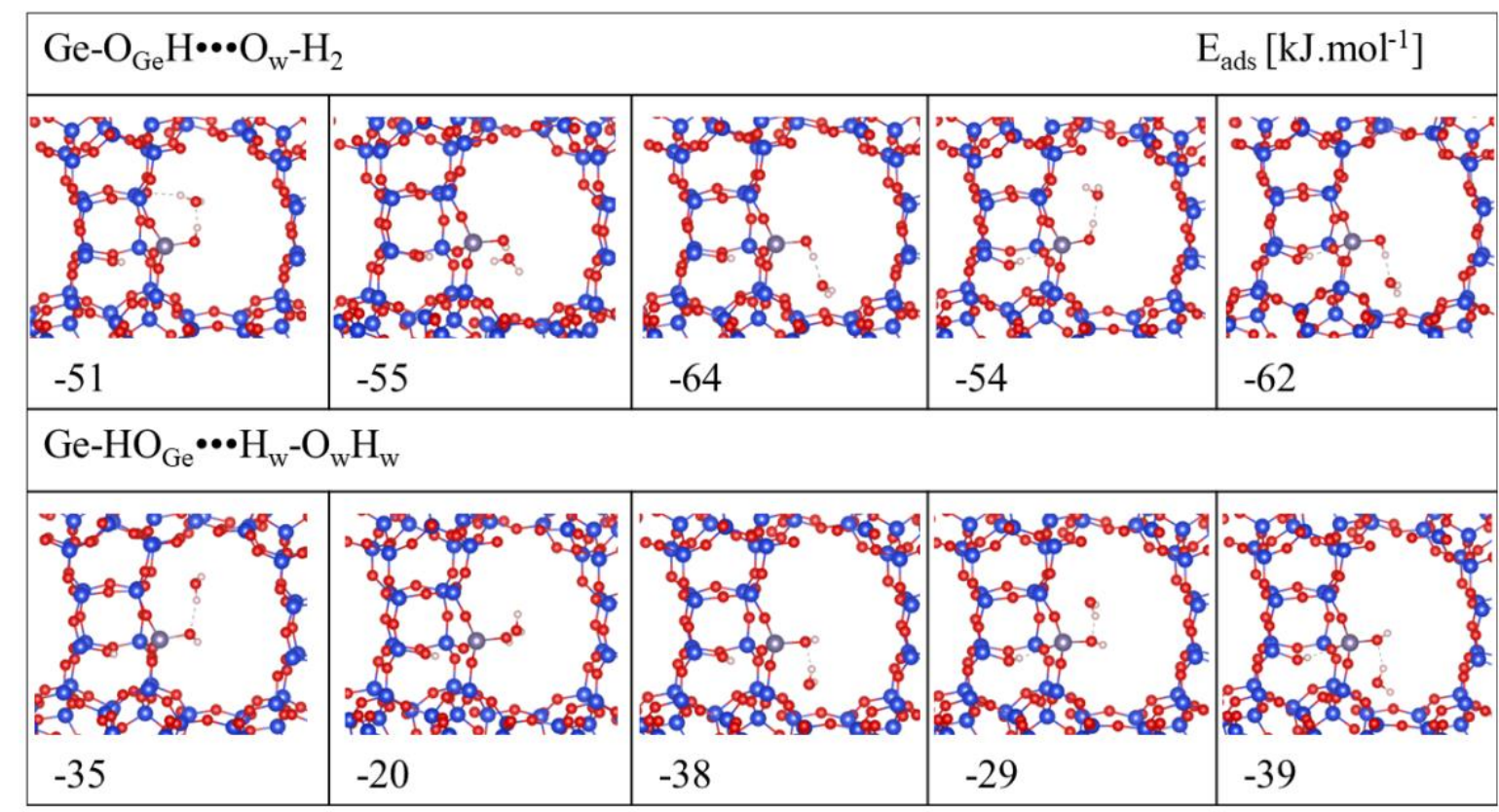




\subsection{Chemisorption at high water regime - Ge-poor UTL mode}

a)
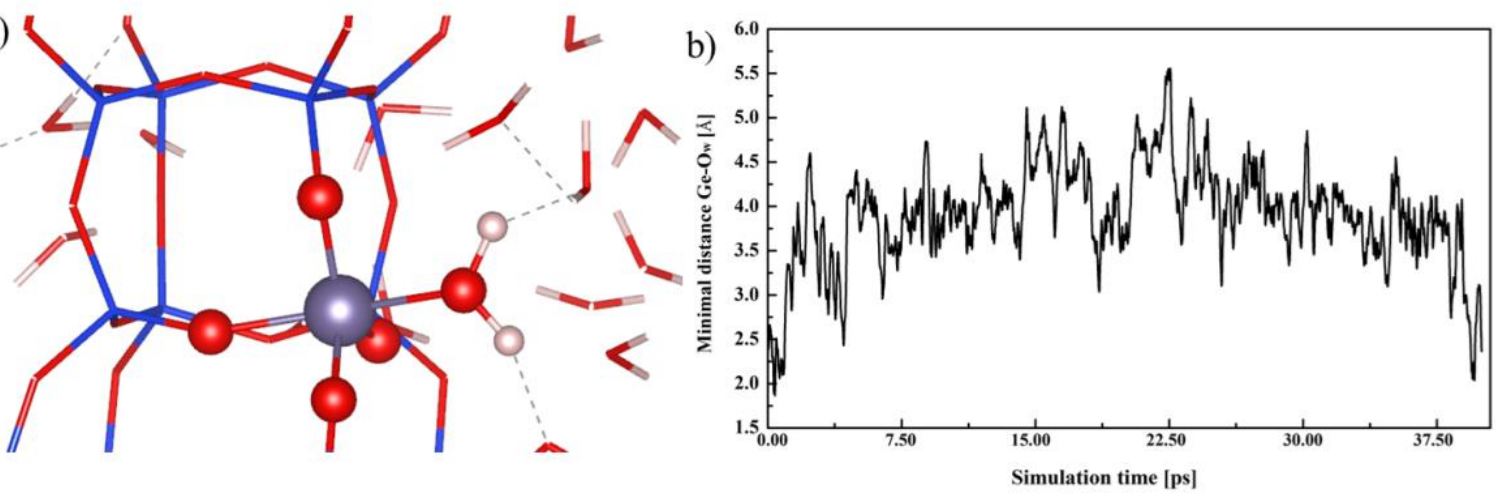

Figure S15: a) The snapshot from the AIMD simulation of 1Ge-UTL model immersed in water solvent $\left(18 \mathrm{H}_{2} \mathrm{O} / \mathrm{UC}\right)$ with one water bound to $\mathrm{Ge}$ atom, forming a five-coordinated $\mathrm{Ge}$ center. $\mathrm{b}$ ) The minimal distance between all $\mathrm{O}$ atoms from water solvent and the Ge atom during AIMD simulation.

Table S4: The summary of the free energy activation energies $\Delta \mathbf{A}^{\neq}$and reaction energies $\Delta \mathbf{A}_{\mathbf{r x n}}$ for axial and $S 2 R$ mechanisms obtained through thermodynamic integration of constrained ab initio molecular dynamics simulations for multiple UTL models.

\begin{tabular}{lll}
\hline$\left[\mathbf{k J} . \mathbf{m o l}^{-1}\right]$ & $\boldsymbol{\Delta A}^{\neq}$ & $\boldsymbol{\Delta A}_{\mathbf{r x n}}$ \\
\hline Axial mechanism & & \\
1Ge-UTL & $37 \pm 2$ & $11 \pm 2$ \\
2Ge-UTL & 39 & 13 \\
\hline S2R mechanism & & \\
2Ge-UTL & $13 \pm 1$ & $8 \pm 1$ \\
3Ge-UTL & $7 \pm 1$ & $-12 \pm 1$ \\
4Ge-UTL (perpendicular) & $0 \pm 1$ & $-52 \pm 2$ \\
4Ge-UTL (parallel) & 0 & -34 \\
8Ge-UTL & $11 \pm 1$ & $-40 \pm 2$ \\
\hline
\end{tabular}
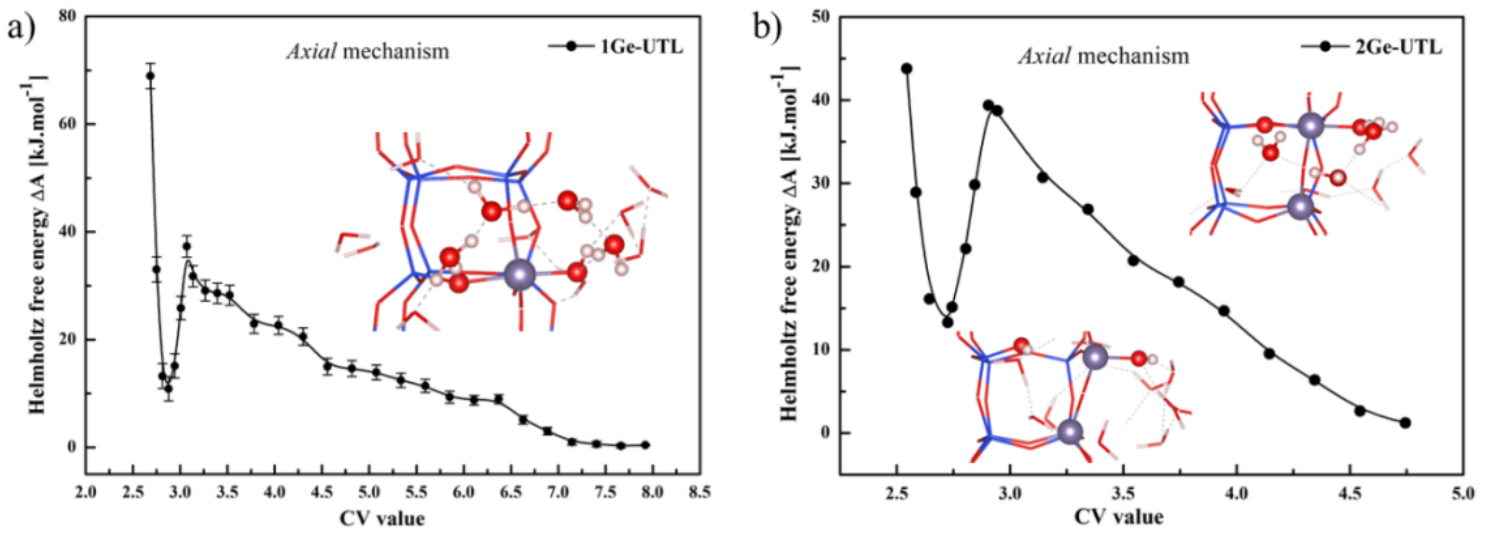
Figure S16: Reaction profiles for axial hydrolytic mechanism in a) 1Ge-UTL, and b) 2 GeUTL models immersed in water solvent $\left(18 \mathrm{H}_{2} \mathrm{O} / \mathrm{UC}\right)$.

Analysis of the lability of Ge-O bond in axial position. To shed light on the seemingly larger lability of framework oxygen in axial position to incoming water in comparison to oxygens in equatorial positions, we carried out multiple analyses of the five-coordinated Ge center, namely bond-length analysis, Mulliken population analysis, electrostatic potential map and projected density of states (see Figures S17-18 and Table S6). These analyses clearly show that framework oxygen in axial position $\mathrm{O}_{a x}$ should be more reactive than equatorial oxygen $\mathrm{O}_{\mathrm{eq}}$ as

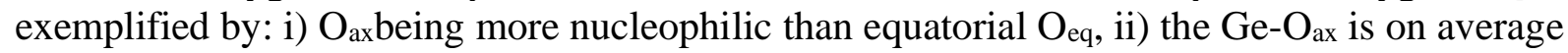
longer than $\mathrm{Ge}-\mathrm{O}_{\mathrm{eq}}$, and iii) that the top of the valence band is occupied primarily by electron density at $\mathrm{O}_{\mathrm{ax}}$.

a)

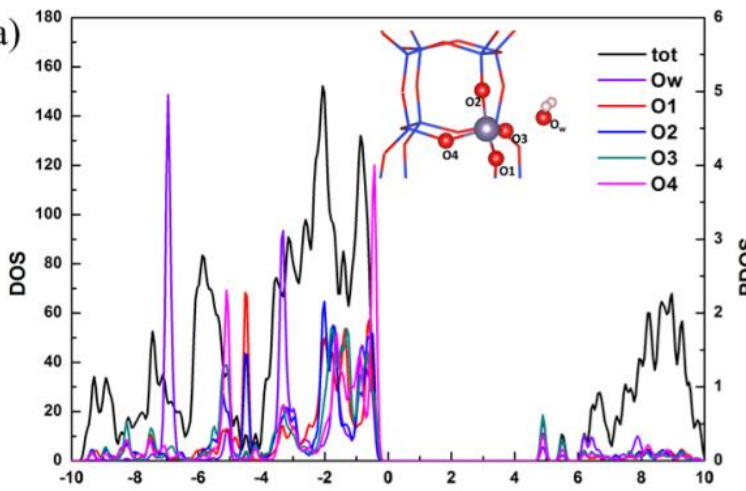

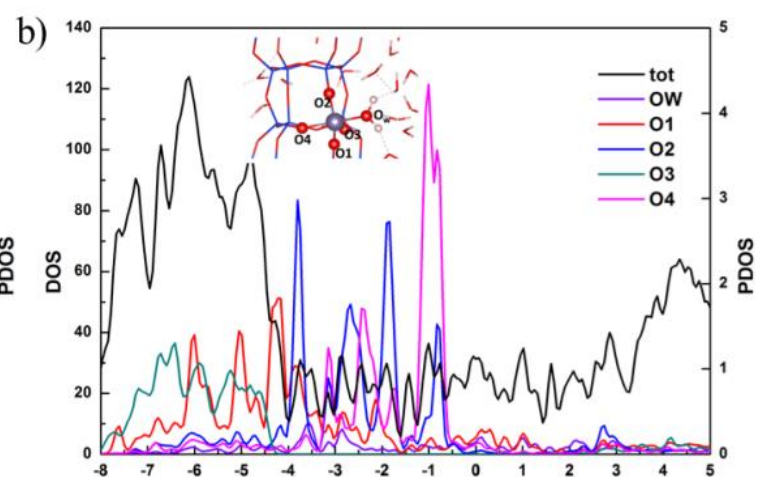

Figure S17: The total and partial density of states (DOS) and (PDOS) of a) water-adsorption complex in the 1Ge-UTL model with a single $\mathrm{H}_{2} \mathrm{O} / \mathrm{UC}$ (DFT-optimized structure), b) wateradsorption complex in the 1Ge-UTL model with a $18 \mathrm{H}_{2} \mathrm{O} / \mathrm{UC}$ (water molecule is bound to germanium - Ge-Ow bond $=1.95 \AA$ ) - a snapshot from the AIMD simulation. Zero energy gives the position of the Fermi level.

Table S5: Mulliken charges and Ge-O bond lengths for: a) water-adsorption complex in the 1Ge-UTL model with a single $\mathrm{H}_{2} \mathrm{O} / \mathrm{UC}$ (DFT-optimized structure), b) water-adsorption complex in the 1Ge-UTL model with a $18 \mathrm{H}_{2} \mathrm{O} / \mathrm{UC}$ (water molecule is bound to germanium Ge-Ow bond $=1.95 \AA$ ) - a snapshot from the AIMD simulation. See Figure S17 for notation.

\begin{tabular}{lll}
\hline & Static & $\begin{array}{l}\text { A snapshot from AIMD with } \\
\text { 5-coordinated Ge center }\end{array}$ \\
\hline Mulliken charge [eV] & & \\
Ow & -0.94 & -0.87 \\
O1 & -1.07 & -1.04 \\
O2 & -1.07 & -1.07 \\
O3 & -1.08 & -1.04 \\
O4 & -1.09 & -1.07 \\
\hline Ge-O bond length $[\AA]$ & & \\
Ge-Ow & 2.440 & 1.956 \\
Ge-O1 & 1.776 & 1.835 \\
Ge-O2 & 1.780 & 1.770 \\
Ge-O3 & 1.785 & 1.803 \\
Ge-O4 & 1.803 & 1.902 \\
\hline
\end{tabular}


a)

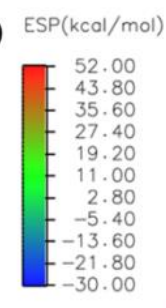

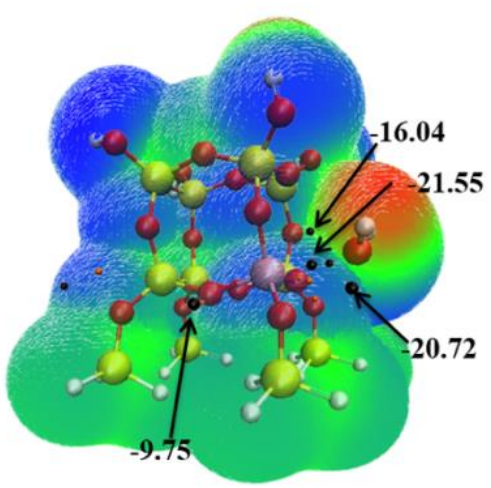

b)

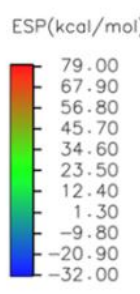

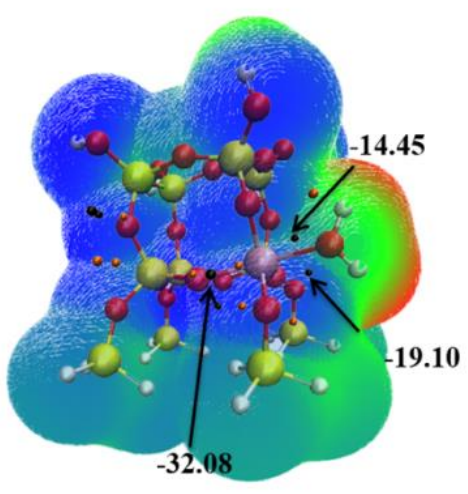

Figure S18: The surface electrostatic potential (ESP) of the water-adsorption complex in the 1Ge-UTL cluster model with a single $\mathrm{H}_{2} \mathrm{O}$ adsorbed on $\mathrm{Ge}$ atom with the structures taken from: a) static DFT structural optimization of periodic 1Ge-UTL model with a single $\mathrm{H}_{2} \mathrm{O} / \mathrm{UC}$, b) a snapshot from the AIMD simulation of the 1Ge-UTL model with a $18 \mathrm{H}_{2} \mathrm{O} / \mathrm{UC}$ - other $17 \mathrm{H}_{2} \mathrm{O}$ were deleted when calculating ESP. The representative values of ESP close to axial and equatorial oxygen atoms are highlighted in black. The more negative ESP value, the stronger the interaction of a nucleophile (e.g., proton) with the framework oxygen is expected to be. ESP potentials for the cluster models were calculated with Gaussian $09^{[7]}$.

Further hydrolytic steps in Ge-poor UTL models. We also calculated later hydrolysis steps $\left(\mathrm{Q}^{3}->\mathrm{Q}^{2}\right)$ for $\mathrm{T} 1$ site in the Ge-poor $\mathbf{U T L}$ environment according to both equatorial and axial mechanisms, since decrease of activation barrier in the first $Q^{4}->Q^{3}$ step was found to be ratelimiting under low-water conditions and we wanted to gauge how much the water loading would influence the later hydrolysis steps that are now expected to be rate-limiting. Our preliminary tests (see Figure S19) show that the next hydrolysis step, the $\mathrm{Q}^{3}->\mathrm{Q}^{2}$ step, faces a similar activation barrier in both high and low water conditions $\left(\sim 70-80 \mathrm{~kJ}^{-\mathrm{mol}^{-1}}\right)$. In addition, preliminary tests also show that the axial and equatorial mechanism become competitive for $\mathrm{Q}^{3}->\mathrm{Q}^{2}$ step, possibly, as a consequence of the presence of interfering nucleophilic center, i.e. the oxygen of silanol and germanol group, that attracts the proton and can recombine to form the water molecule in an equatorial position to the initially adsorbed water (see Figure S19). Increased water content was also shown previously ${ }^{[8-9]}$ to mildly decrease the activation barrier for equatorial hydrolysis mechanism in dealumination of CHA and MFI zeolites, by 10-20 $\mathrm{kJ} . \mathrm{mol}^{-1}$, profiting from the collective action of multiple water molecules in a similar way as observed in axial mechanism here. Our tests, using a cluster model of D4R unit with a single Ge site, indeed confirm that cooperativity between water molecules is able to decrease the equatorial barrier for Ge-O-Si hydrolysis by approx. $10 \mathrm{~kJ} \cdot \mathrm{mol}^{-1}$ (see Figure S20). Hence, we might hypothesize that in Ge-poor UTL under high water loading conditions the rate-limiting step will shift towards later hydrolysis steps $\left(\mathrm{Q}^{3}->\mathrm{Q}^{2}, \mathrm{Q}^{2}->\mathrm{Q}^{1}\right.$ and $\mathrm{Q}^{1}->\mathrm{Q}^{0}$ steps $)$. However, increased water content is expected to at least partially decrease the activation barriers across the board and thus ease the hydrolysis as a whole. 

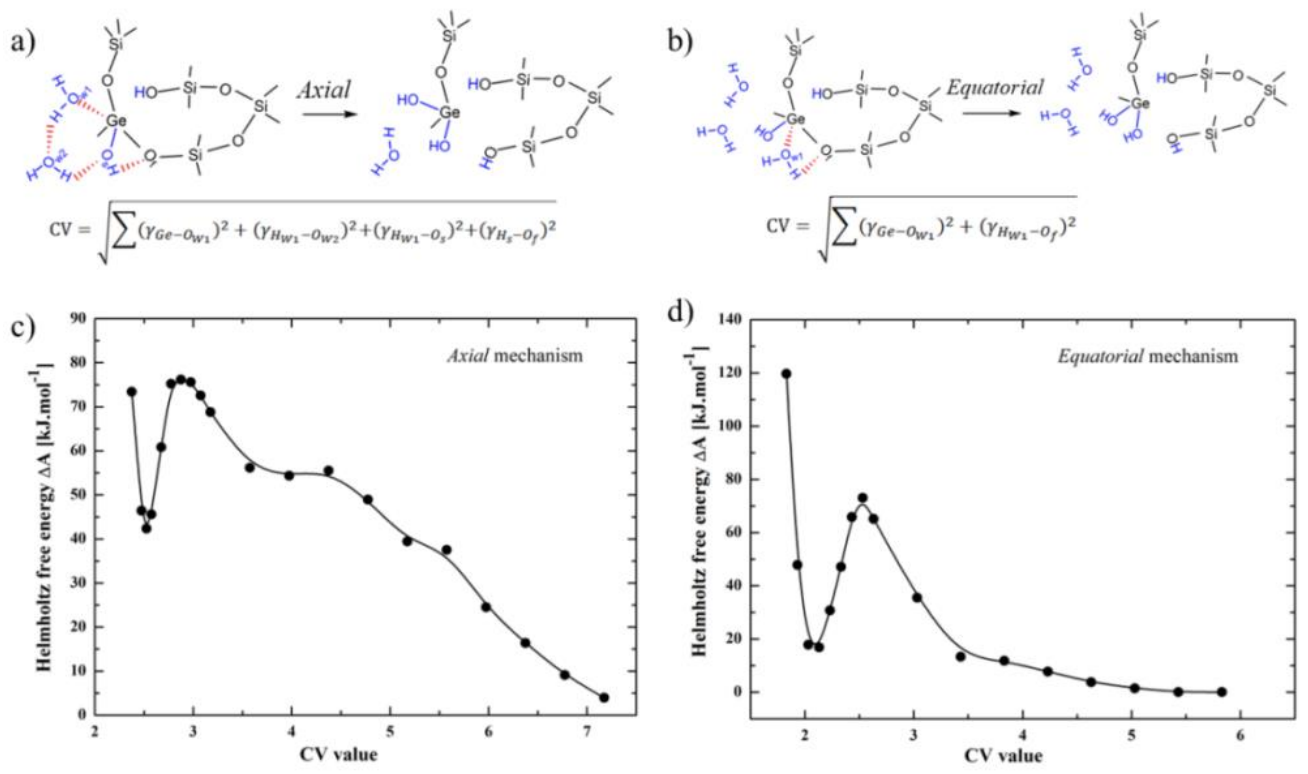

Figure S19: Free energy reaction profiles for the second hydrolysis step, i.e., $Q^{3}->Q^{2}$ step, (calculated at $370 \mathrm{~K}$ ) in the $\mathbf{1 G e - U T L}$ model with a $18 \mathrm{H}_{2} \mathrm{O} / \mathrm{UC}$. The schemes of the a) axial and $b$ ) equatorial mechanism for the second hydrolysis step along with the definitions of collective variables $(\mathrm{CVs})$ are provided above. Below, the corresponding free energy profiles for c) axial, and d) equatorial mechanisms are shown. Atoms initially present in the zeolite framework are depicted in black and atoms originating from the water solvent are depicted in blue. Bonds involved in the CVs are shown in red.
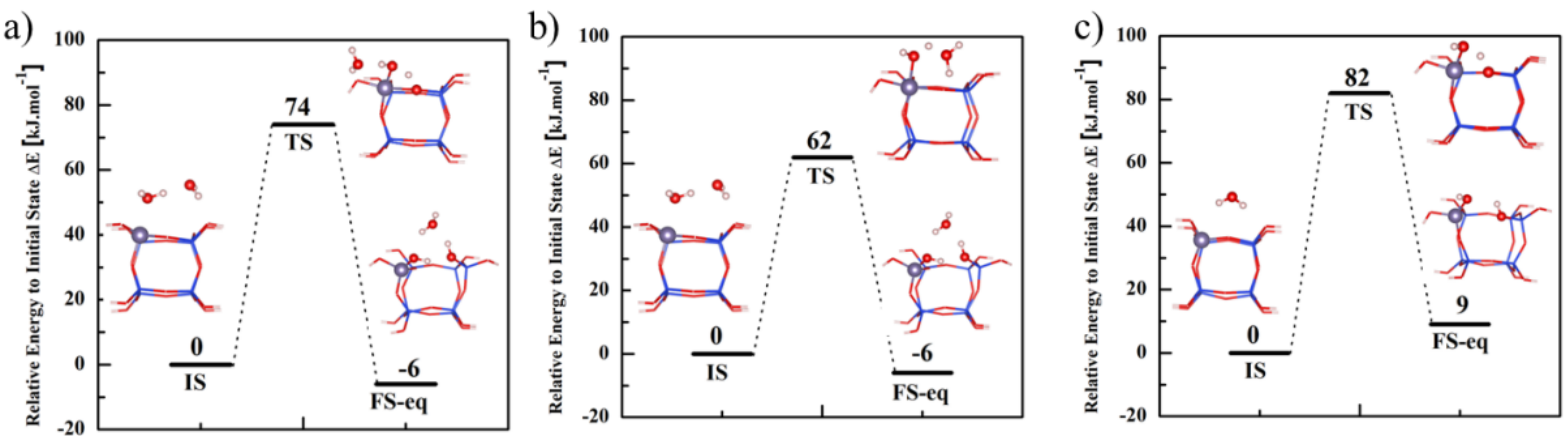

Figure S20: The reaction profile for the equatorial mechanisms with two (a-b) and one (c) water molecules over $1 \mathrm{Ge}$ substituted D4R unit cluster model. Figures of reactants, products and transition states are provided as insets.. In a), one $\mathrm{H}_{2} \mathrm{O}$ molecule reacts with Ge site, splits and breaks the Ge-O bond, while the other $\mathrm{H}_{2} \mathrm{O}$ molecule is a spectator interacting with the silanol nearby and the incoming water, with a barrier of $74 \mathrm{~kJ}^{-\mathrm{mol}^{-1}}$. In b) both of the water molecules participate in the Ge-O breaking and short proton shuttle: one $\mathrm{H}_{2} \mathrm{O}$ adsorbs on $\mathrm{Ge}$ and transfers a proton to the other, while the other $\mathrm{H}_{2} \mathrm{O}$ transfers a proton to the oxygen nearby $\mathrm{Ge}$ breaking the Ge-O bond in the process. The barriers of the second mechanism are $62 \mathrm{~kJ}^{-\mathrm{mol}^{-}}$ 1. In c) a single water molecule interacts with the Ge-site following the standard equatorial mechanism resulting in a barrier of $82 \mathrm{~kJ} \mathrm{~mol}^{-1}$. According to results, involvement of the second water can decrease reaction barrier by $10-20 \mathrm{~kJ} \mathrm{~mol}^{-1}$. All calculations for the cluster models were carried out with Gaussian 09 ${ }^{[7]}$. 


\subsection{Chemisorption at high water regime - Ge-rich UTL model}
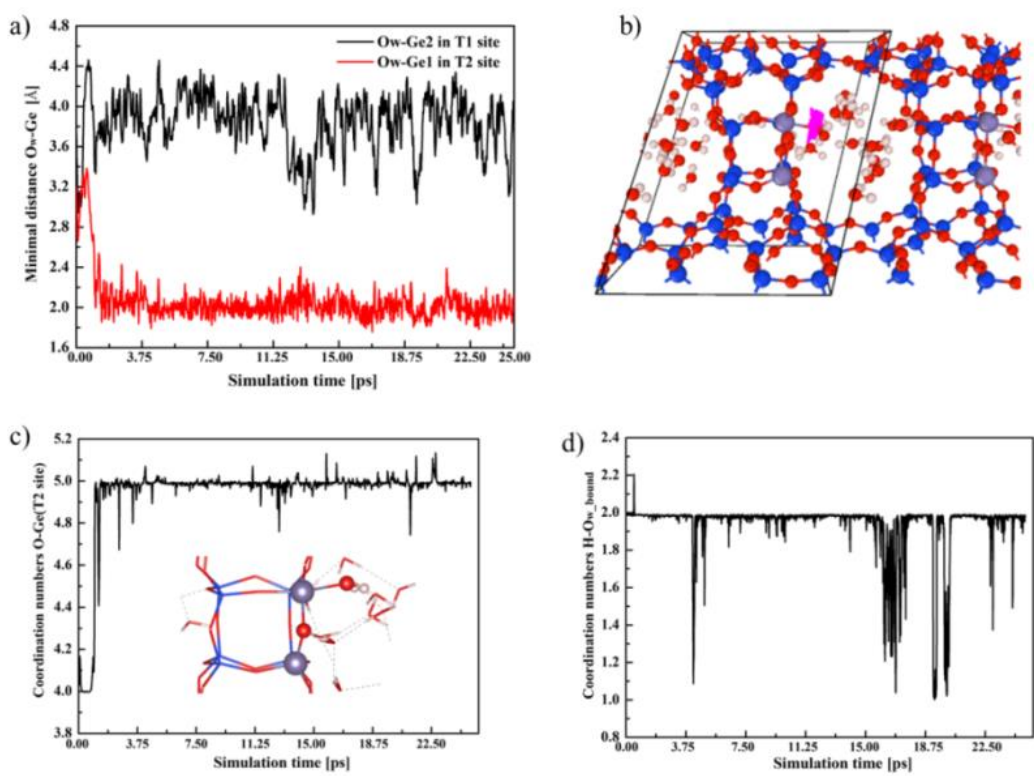

Figure S21: Time evolution of multiple characteristics obtained from equilibrium AIMD simulations of the 2Ge-UTL model with $18 \mathrm{H}_{2} \mathrm{O} / \mathrm{UC}$. a) The minimal distance between an oxygen atom from the water and Ge atoms in either T1 or T2 site. b) Structure of the 2Ge-UTL model with a $18 \mathrm{H}_{2} \mathrm{O} / \mathrm{UC}$ with the trajectory line (in pink) depicting movement of the water molecule starting close to the Ge-O-Ge unit and then binding to the $\mathrm{Ge}$ atom in the $\mathrm{T} 2$ site. c) The coordination number of the Ge atom in the $\mathrm{T} 2$ site (with respect to all oxygen atoms in the unit cell) with the structure of the five-coordinated Ge center in the inset. d) The coordination number of the oxygen atom of the water (bound to $\mathrm{Ge}$ atom in the $\mathrm{T} 2$ site) with respect to all the hydrogens in the unit cell.
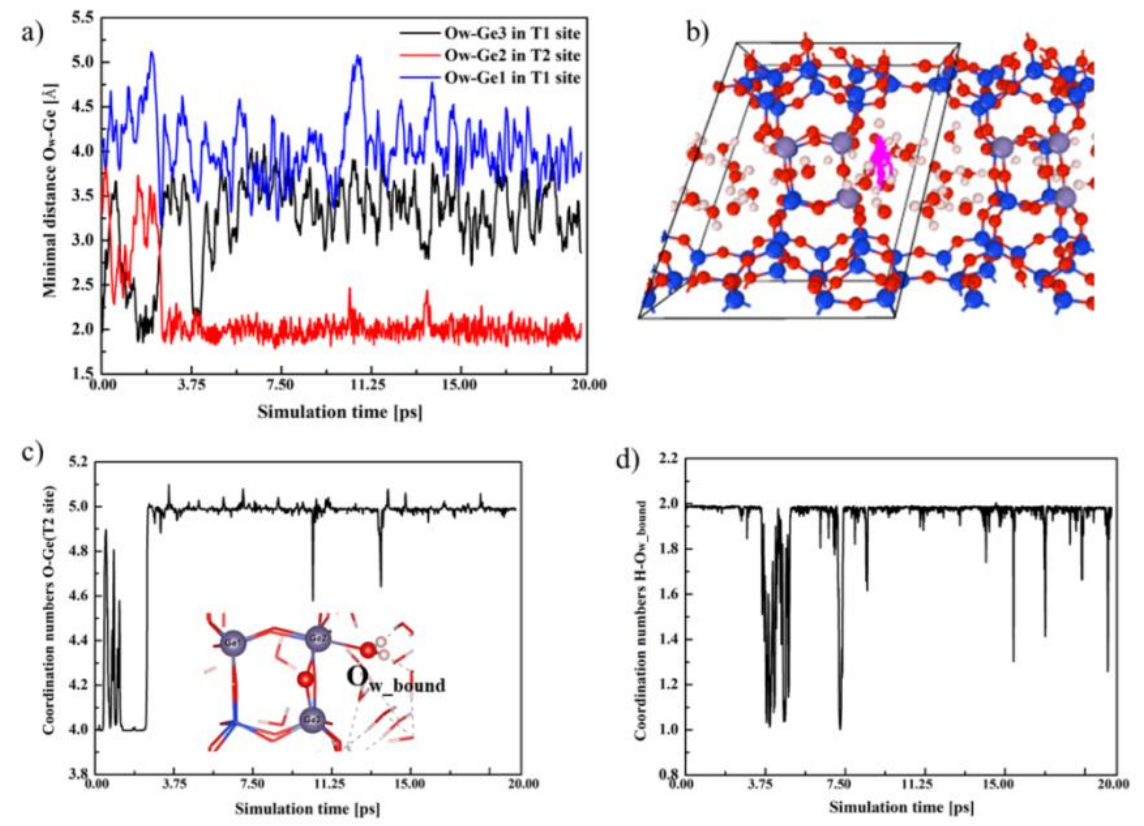

Figure S22: Time evolution of multiple characteristics obtained from equilibrium AIMD simulations of 3Ge-UTL model with a $18 \mathrm{H}_{2} \mathrm{O} / \mathrm{UC}$. a) The minimal distance between the 
oxygen atom from the water and the three Ge atoms in the D4R unit. b) Structure of the 3GeUTL model with $18 \mathrm{H}_{2} \mathrm{O} / \mathrm{UC}$ with the trajectory line (in pink) depicting movement of the water molecule starting close to the Ge-O-Ge unit and then binding to the Ge2 atom in the T2 site. c) The coordination number of the $\mathrm{Ge}$ atom in the $\mathrm{T} 2$ site (with respect to all oxygen atoms in the unit cell) with the structure of the five-coordinated Ge center in the inset. d) The coordination number of the oxygen atom of the water (bound to $\mathrm{Ge}$ atom in the $\mathrm{T} 2$ site) with respect to all the hydrogens in the unit cell.

Alternative 4Ge-UTL model with germanium atoms in S4R parallel to the UTL layer. We also considered an alternative distribution of germanium atoms in the 4Ge-UTL model, putting all germanium atoms in the S4R ring parallel with the layer (see Figs. S23c-d, S25 and Table S5) rather than in the S4R ring perpendicular to the layer. The motivation is that the hydrolysis of an S4R ring parallel to the layer is expected to allow layer delamination ${ }^{[10]}$. We observed that these two 4Ge-UTL models behave qualitatively the same and hence the orientation of the germanium-filled S4R ring in the D4R unit is not expected to play a significant role in the UTL reactivity.

a)

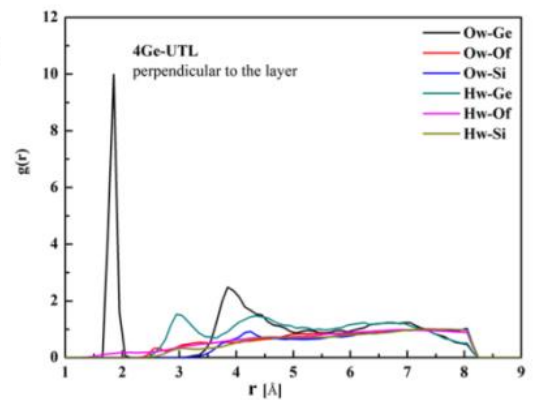

c)

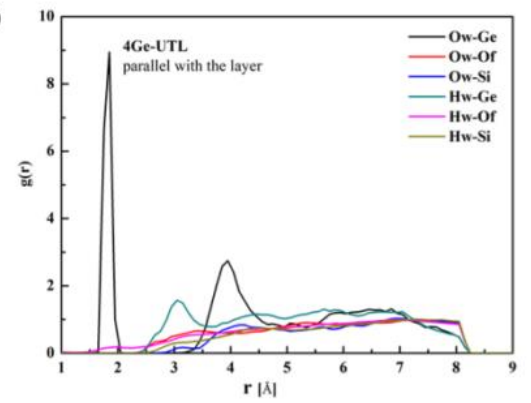

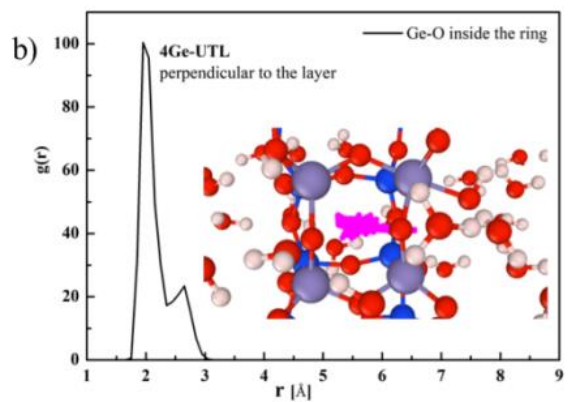

d)

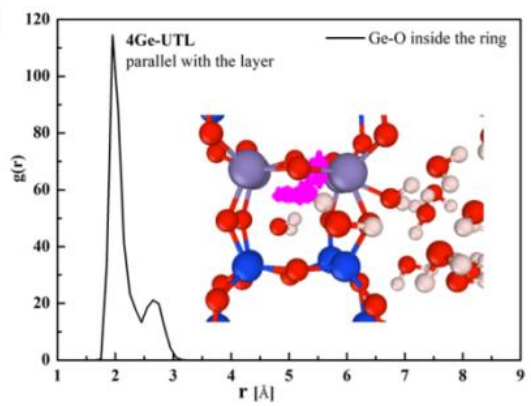

Figure S23: The partial radial distribution functions (prdfs) between multiple atom (type) pairs for two 4Ge-UTL models considered in the work with 4 Ge atoms clustered in S4R ring a-b) perpendicular to the layer, c-d) parallel to the layer. The structures of the 4Ge-UTL models inserted in the b) and d) contain the trajectory lines (in pink) of the $\mathrm{O}$ atom moving inside the S4R ring. The group of atoms between which the prdfs are evaluated are: a) and c) defined in Figure S10 above, $b$ ) and d) between all Ge atoms and the oxygen atom moving in the S4R ring. 

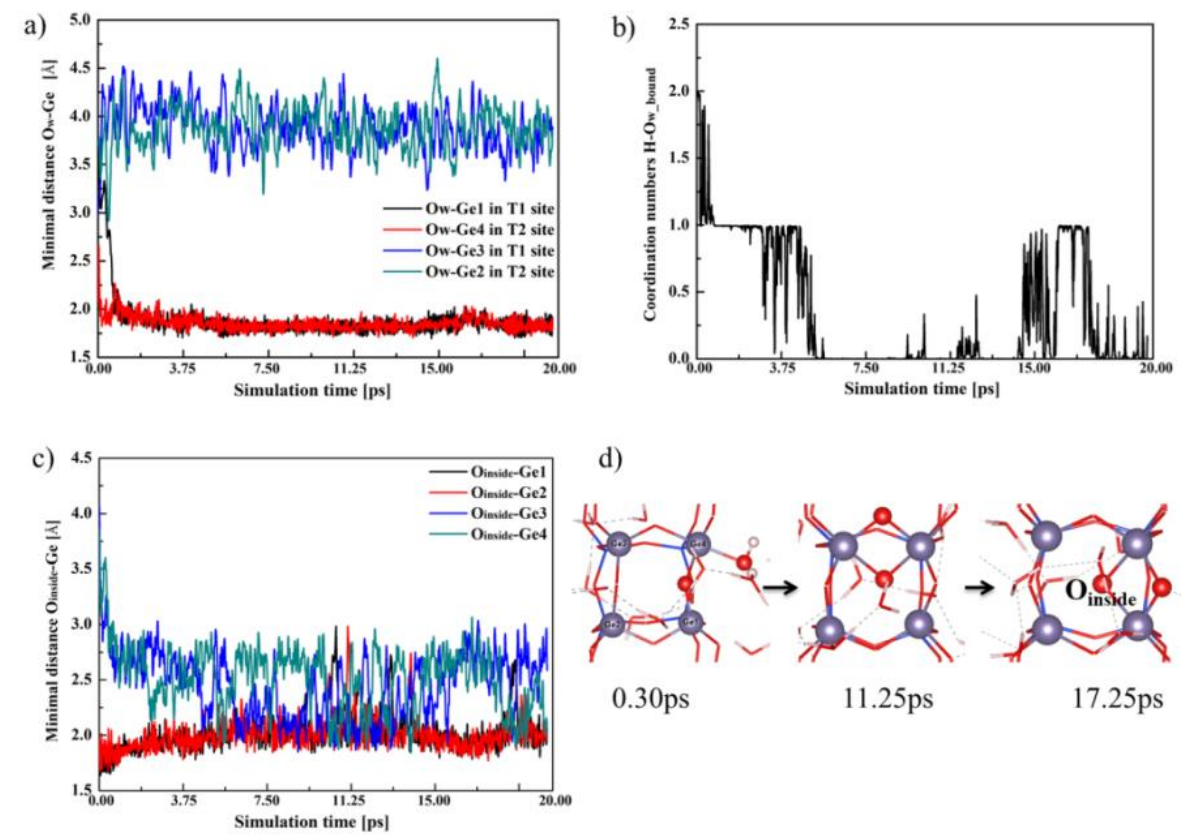

d)

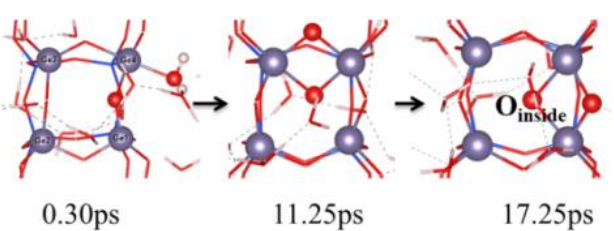

Figure S24: Time evolution of multiple characteristics obtained from equilibrium AIMD simulations of the 4Ge-UTL model with $18 \mathrm{H}_{2} \mathrm{O} / \mathrm{UC}$ (and $\mathrm{Ge}$ atoms in an S4R perpendicular to the layer). a) The minimal distance between the $\mathrm{O}$ atom from the water and all four $\mathrm{Ge}$ atoms in the D4R unit. b) The coordination number of the oxygen atom of the water (bound to $\mathrm{Ge}$ atom(s)) with respect to all the hydrogens in the unit cell. c) The minimal distance between $\mathrm{O}$ inside the ring and each Ge atom. d) Representative snapshots from the trajectory depicting gradual deprotonation of the incoming water molecule, formation of the $S 2 R$ product, i.e. the $\mathrm{Ge}-\left(\mathrm{O}_{\mathrm{f}}\right)\left(\mathrm{O}_{\mathrm{w}}\right)-\mathrm{Ge}$ unit, and movement of the oxygen inside the S4R ring.
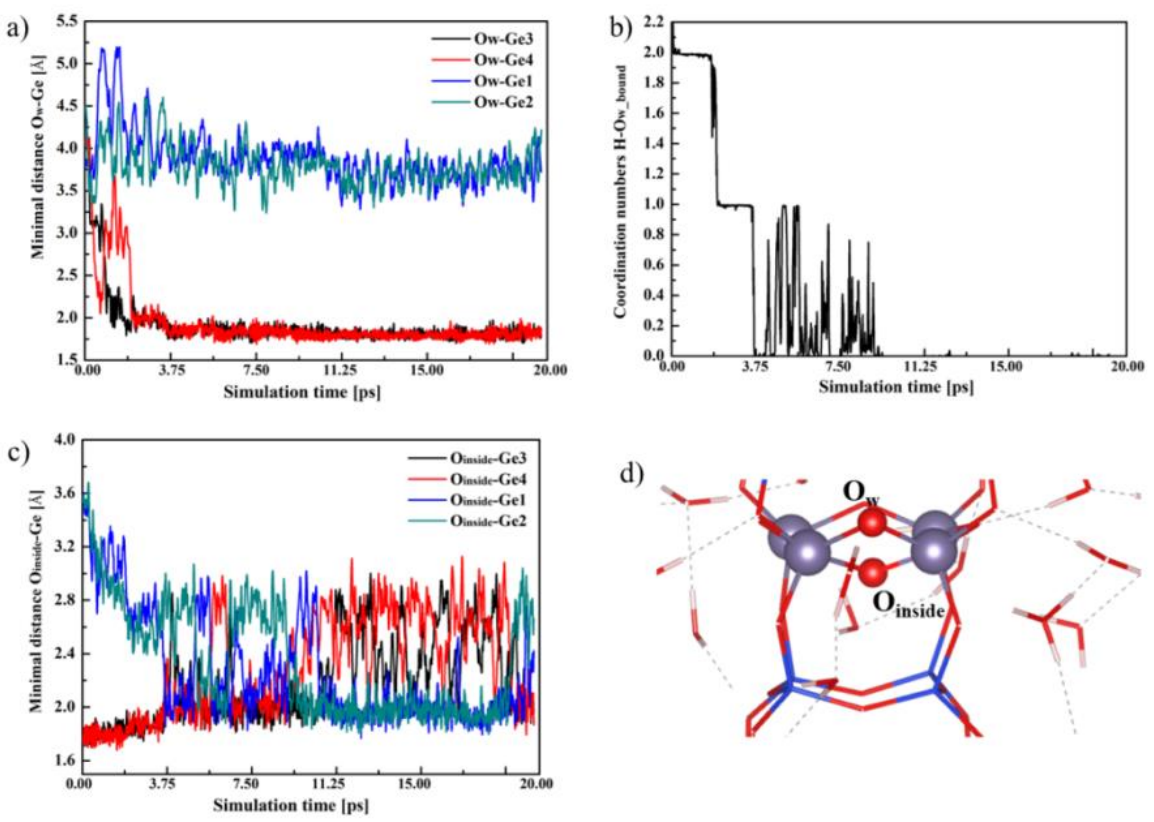

Figure S25: Time evolution of multiple characteristics obtained from equilibrium AIMD simulations of the 4Ge-UTL model with $18 \mathrm{H}_{2} \mathrm{O} / \mathrm{UC}$ (and Ge atoms in S4R parallel to the layer). a) The minimal distance between the $\mathrm{O}$ atom from the water and all four Ge atoms in the $\mathrm{D} 4 \mathrm{R}$ unit. b) The coordination number of the oxygen atom of the water (bound to Ge atom(s)) with respect to all the hydrogens in the unit cell. c) The minimal distance between $\mathrm{O}$ inside the ring and each $\mathrm{Ge}$ atom. d) The representative snapshot from the trajectory depicting the $S 2 R$ product, i.e. the $\mathrm{Ge}-\left(\mathrm{O}_{\mathrm{f}}\right)\left(\mathrm{O}_{\mathrm{w}}\right)-\mathrm{Ge}$ unit, with the definition of the $\mathrm{O}_{\mathrm{w}}$ and $\mathrm{O}_{\text {inside }}$ oxygen atom types. 

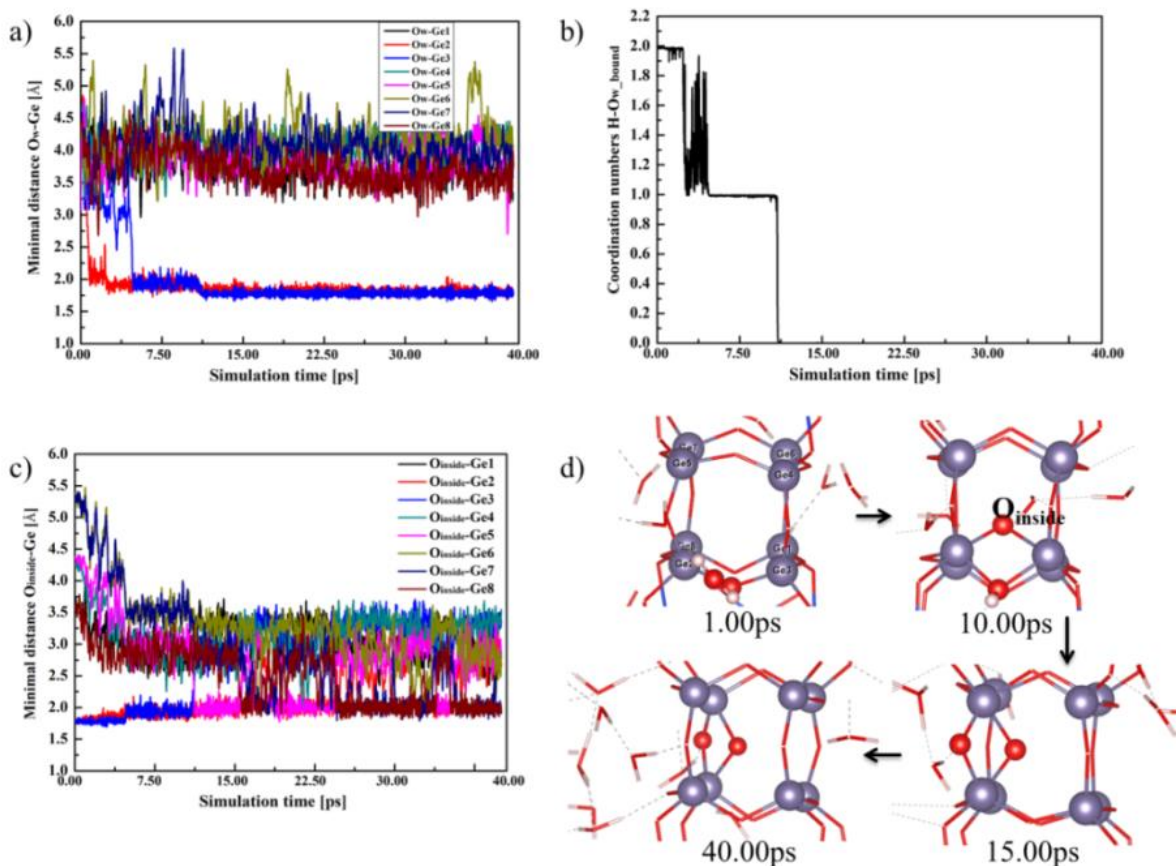

Figure S26: Time evolution of multiple characteristics obtained from equilibrium AIMD simulations of the 8Ge-UTL model with $18 \mathrm{H}_{2} \mathrm{O} / \mathrm{UC}$ (and Ge atoms fully occupying the D4R unit). a) The minimal distance between the $\mathrm{O}$ atom from the water and all eight $\mathrm{Ge}$ atoms in the D4R unit. b) The coordination number of the oxygen atom of the water (bound to Ge atom(s)) with respect to all the hydrogens in the unit cell. c) The minimal distance between $\mathrm{O}$ inside the ring and each Ge atom. d) The representative snapshots from the trajectory depicting gradual deprotonation of the incoming water molecule, formation of the S2R product, i.e. the Ge$\left(\mathrm{O}_{\mathrm{f}}\right)\left(\mathrm{O}_{\mathrm{w}}\right)-\mathrm{Ge}$ unit, and movement of the oxygen inside the $\mathrm{D} 4 \mathrm{R}$ unit.
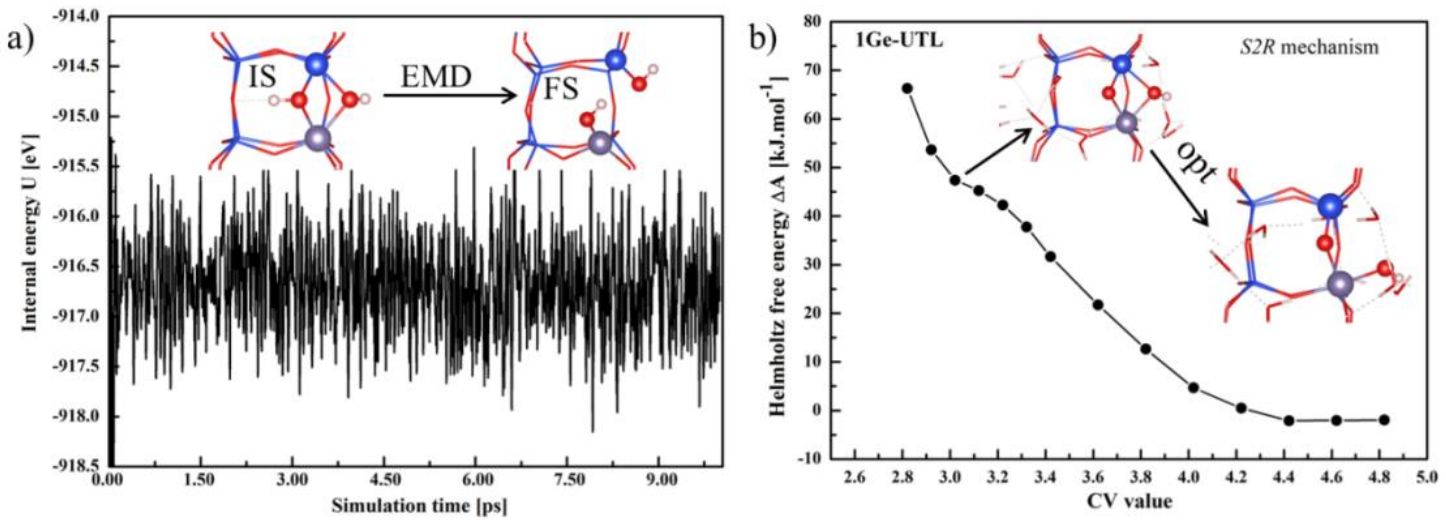

Figure S27: a) The evolution of internal energy during the equilibrium AIMD simulations for 1Ge-UTL model with a geminal product formed initially (no water present in the unit cell) the geminal product is unstable and gradually transforms into the equatorial product (illustrated in the inset figures). b) The Helmholtz free energy reaction profile for the 1Ge-UTL model with a geminal product and $18 \mathrm{H}_{2} \mathrm{O} / \mathrm{UC}$ - the geminal product does not represent a local minimum and transforms into the water bound to Ge atom, i.e., the five-coordinated Ge center. 
a)

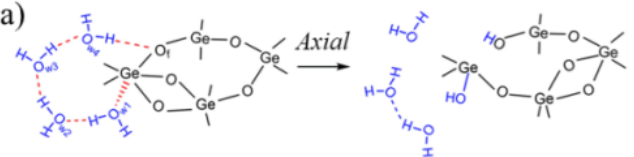

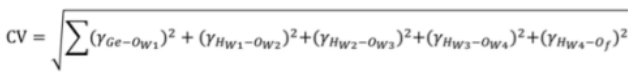

c)

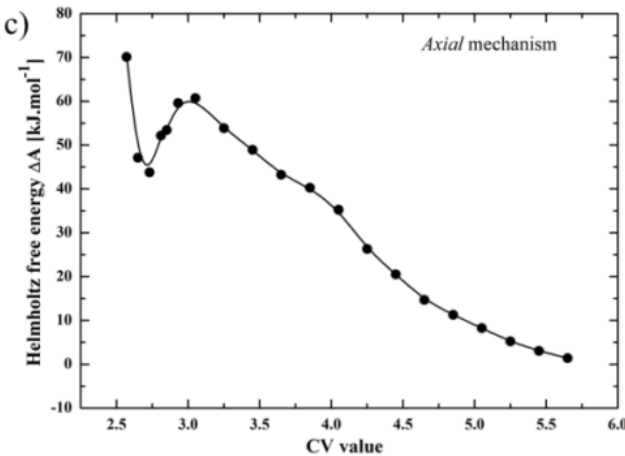

b)
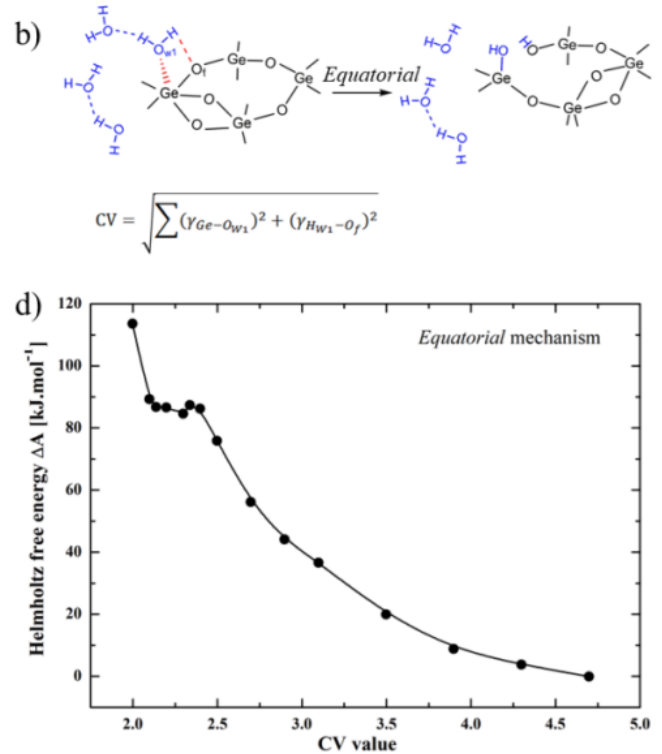

Figure S28: Further decomposition steps starting from the $S 2 R$ product (formed in the initial hydrolysis step from the pristine 8Ge-UTL model with $18 \mathrm{H}_{2} \mathrm{O} / \mathrm{UC}$ ). The schemes of the a) axial and b) equatorial mechanism for the second hydrolysis step along with the definitions of collective variables $(\mathrm{CVs})$ are provided above. Below, the corresponding free energy profiles for c) axial, and d) equatorial mechanisms are shown. Atoms initially present in the zeolite framework are depicted in black and atoms originating from the water solvent are depicted in blue. Bonds involved in the CVs are shown in red.
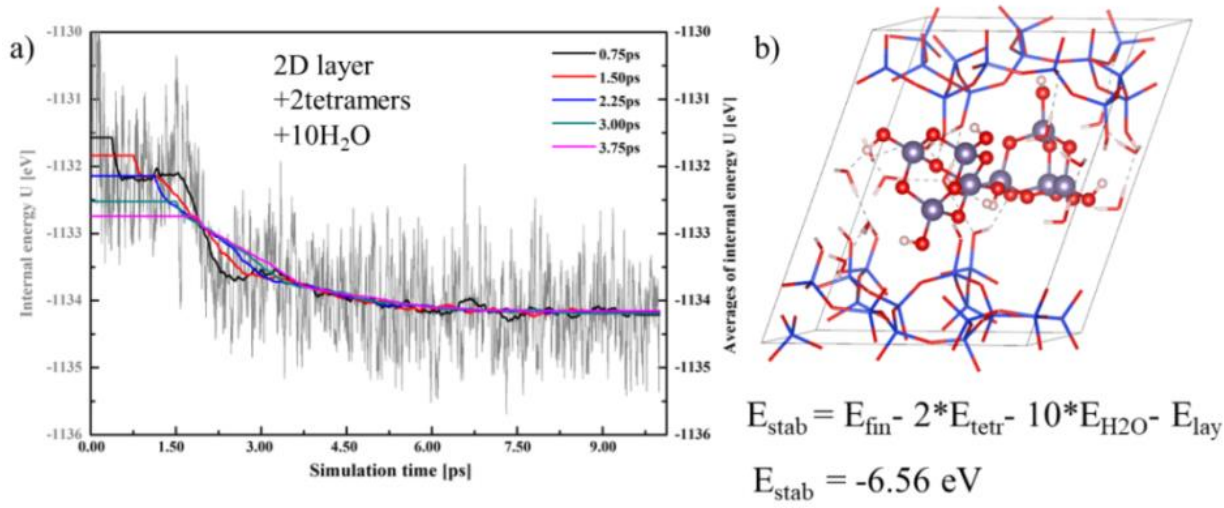

Figure S29: a) The running averages of the internal energy $U$ from equilibrium AIMD simulations of one of the plausible hydrolysis products, i.e., the two hydroxylated germanium oxide tetramers (formed from Ge-filled D4R unit), embedded between the UTL layers and solvated by ten water molecules, b) The stabilization energy of this plausible hydrolysis products compared to energy of the isolated components (UTL layers, germanium oxide tetramer) and water (in liquid reference state).

\section{References:}

[1] Database of Zeolite Structures. http://www.iza-structure.org/databases/ (accessed Mar 2, 2021). 
[2] Pronk, S.; Pall, S.; Schulz, R.; Larsson, P.; Bjelkmar, P.; Apostolov, R.; Shirts, M. R.; Smith, J. C.; Kasson, P. M.; Spoel, D. v.; Hess, B.; Lindahl, E. GROMACS 4.5: a highthroughput and highly parallel open source molecular simulation toolkit. Bioinformatics 2013, $29,845-854$.

[3] Menzinger, M.; Wolfgang,R. The Meaning and Use of the Arrhenius Activation Energy. Angew. Chem. internat. Edit. 1969, 8, 438-444.

[4] Smith, J. D.; Cappa, C. D.; Wilson, K. R.; Messer, B. M.; Cohen, R. C.; Saykally, R. J. Energetics of Hydrogen Bond Network Rearrangements in Liquid Water. Science 2004, 306, $851-853$.

[5] Kuo, I.-F. W.; Mundy, C. J._An Ab Initio Molecular Dynamics Study of the Aqueous LiquidVapor Interface. Science 2004, 303, 658-660.

[6] Krossner, M.; Sauer, J. Interaction of Water with Brønsted Acidic Sites of Zeolite Catalysts.Ab Initio Study of 1:1 and 2:1 Surface Complexes. J. Phys. Chem. 1996, 100, 61996211.

[7] Frisch, M. J.; Trucks, G. W.; Schlegel, H. B.; Scuseria, G. E.; Robb, M. A.; Cheeseman, J. R.; Scalmani, G.; Barone, V.; Petersson, G. A.; Nakatsuji, H. et al., Gaussian 09, Revision A.02, Gaussian, Inc., Wallingford CT, 2009.

[8] Nielsen, M.; Hafreager, A.; Brogaard, R. Y.; Wispelaere, K. D.; Falsig, H.; Beato, P.; Speybroeck, V. V.; Svelle, S. Collective action of water molecules in zeolite dealumination. Catal. Sci. Technol.2019, 9, 3721-3725.

[9] Stanciakova, K.; Ensing, B.; Göltl, F.; Bulo, R. E.; Weckhuysen, B. M. Cooperative Role of Water Molecules during the Initial Stage of Water-Induced Zeolite Dealumination. ACS Catal. 2019, 9, 5119-5135.

[10] Kasian, N.; Tuel, A.; Verheyen, E.; Kirschhock, C. E. A.; Taulelle, F.; Martens, J. A. NMR Evidence for Specific Germanium Siting in IM-12 Zeolite. Chem. Mater. 2014, 26, 19, 55565565 . 